\title{
Can there be a market for cheap-talk information? An experimental investigation
}

\author{
Antonio Cabrales, Francesco Feri, Piero Gottardi \\ and Miguel A. Meléndez-Jiménez*
}

January 2020

\begin{abstract}
This paper reports on experiments testing the viability of markets for cheap-talk information. We find that the level of trade in these markets is very small and eventually vanishes. Sellers provide low-quality information even when doing so does not increase their monetary payoff. This contributes to the low demand in the market for information. Moreover, we observe the same very low level of activity in the market for information when sellers face no conflict of interest and the noise in the quality of the transmitted information is much lower. Hence, we argue that the collapse of the market for information is a demand phenomenon, and even small uncertainty over the quality of information seems to have a large impact.
\end{abstract}

Keywords: Experiment, Cheap Talk, Auction, Information Acquisition, Information Sale JEL Classification: D83, C72, G14

\footnotetext{
* Antonio Cabrales, Dept. of Economics, University College London; Francesco Feri, Dept. of Economics, Royal Holloway University of London and University of Trieste; Piero Gottardi, Dept. of Economics, University of Essex and University of Venice; Miguel A. Meléndez-Jiménez, Dept. Teoría e Historia Económica, Universidad de Málaga. We are grateful to Vince Crawford, the editor, as well as an associate editor and three anonymous referees for very helpful comments. We also thank Andreas Blume, Marco Casari, Matthew Embrey, Peter Eso, Antonio Guarino, Navin Kartik, Meg Meyer, Marco Ottaviani, Santiago Sánchez-Pagés, Joel Sobel, Matthias Sutter, Marc Vorsatz, and seminar participants at the London Behavioral and Experimental Group, University of East Anglia, Università Bocconi, EUI, QMUL, Oxford University, Sussex University, and WZB Berlin for comments. Miguel A. Meléndez-Jiménez acknowledges financial support from the Junta de Andalucía-FEDER through project UMA18-FEDERJA243 and from the Spanish Ministry of Science, Innovation and Universities through Project RTI2018097620-B-I00. All errors are our own.
} 


\section{Introduction}

Information transmission is common in economic life. Transmission occurs even when it is possible to transmit only soft/unverifiable information and when the incentives of senders and receivers do not align. Potential competitors sometimes share information, for example, when recruiters discuss the characteristics of individuals whom they would both like to hire or when corporate raiders discuss potential takeover targets. The drawback of sharing information in this way is that conflicts of interest may make the sources unreliable. However, when information is costly to acquire, market participants can benefit by sharing, perhaps in return for some payment, the information they have acquired - even though the information shared may be noisy - thereby creating a market for information. The lower the rivalry of information or the higher its cost, the more likely soft information is sold and transmitted. The literature on cheap-talk games, starting with Crawford and Sobel (1982), has established a set of conditions for soft strategic information transmission.

This paper reports on a series of experiments testing the viability of a market for information. From a theoretical point of view, the game we designed has an equilibrium where information is indeed exchanged. In addition, previous experimental evidence shows that real subjects often tell the truth, even against their self-interest. This suggests that they derive utility from not breaching a truth-telling norm, and it could strengthen the likelihood of a market for information arising. Thus, both theoretical and experimental reasons support the feasibility of a market for information where the information is unverifiable. In our experiments, however, we find that markets for information are fragile when information is soft. Given the above, this finding is somewhat in contrast with the theoretical predictions and previous experimental evidence. Moreover, we find that when the information exchanged is verifiable, fragility no longer obtains, as the level of activity in the market for information is in line with the theoretical predictions. When information is soft, subjects show a considerably weaker willingness to pay for information, and there is little information exchange. This is due to a lack of trust in information from nonverifiable sources. We find this is true independently of whether there are conflicts of interest between sellers and buyers of information. Hence, the fragility can be attributed to the soft nature of the information.

In our baseline treatment, we use a stylized game in which agents can acquire information by paying a fixed cost. Then, they can sell information to others via 
nonverifiable reports. That is, a seller of information has no commitment to sending reports with correct information. What makes the game relevant for our purposes is that there is a potential conflict of interest. The seller of information may be able to profit directly from the information he acquired by carrying out trades in the market. In that case, he has an interest in misleading the buyers of information since his payoff is decreasing in the number of informed agents. It is important (and also, we argue, realistic) that this conflict of interest does not always exist. That is, these profitable opportunities arise only with some probability, that is, positive but less than one, and when they do not arise, there is no motive to mislead buyers.

Cabrales and Gottardi (2014), henceforth $C G$, characterize the 'informative' equilibria of such a game (when all agents are self-interested and do not have an intrinsic motive to tell the truth). In these equilibria, sellers of information send truthful reports when they have no opportunities to directly use the information. Otherwise, they send an uninformative message. Markets for information are active in equilibrium, provided the cost of acquiring information is not too high. Other equilibria exist, where the buyer of information expects to obtain uninformative messages. As a result, information is not transmitted.

It is of interest to contrast the findings for the above game with those for an alternative game specification. This was the basis for our main experimental control. In that alternative specification, the sellers of information can send only truthful messages, while the rest of the game remains unchanged. In this situation, when the seller prefers that buyers remain uninformed, he can achieve this outcome only by not selling them a report. The equilibrium of this game exhibits the same payoffs as the informative equilibrium of the game with cheap-talk reports. However, there is no equilibrium with outcomes analogous to the babbling equilibrium. We call the game where reports are cheap-talk messages and can then be false the game with soft information, or Soft game for short. We call the game where reports must be truthful the game with hard information or Hard game.

We perform experiments for both the Hard and the Soft games. The only difference between them lies in the quality of information in the reports sold. As argued above, the theoretical prediction is that the information transmitted is the same in the two cases. The random assignment to the treatment then allows us to attribute the cause of differences in outcomes to this feature. We believe that this is a novel experimental 
design. Indeed, how much information will be sold in the market and the role played by the hard vs. soft nature of the information transmitted is an open and relevant empirical question. In contrast, the previous theoretical and empirical literature on communication games tended to emphasize the alignment of preferences between senders and receivers, which we will show is less important in our case.

Our experimental findings allow us to conclude that the market for information in the Soft game does not work well. The quality of information (with respect to the quality predicted by the informative equilibrium in the theoretical analysis mentioned above) is rather poor. The market is extremely small and fragile.

We find that there are far fewer purchases of reports from informed players in the Soft game and, in the last rounds of the experiment on the game, these purchases decline further and practically disappear. This is in contrast with what we get for the Hard game, where we observe that the size of the market for information is much larger and, importantly, does not decrease as the game is repeated.

We should point out that the games briefly described above are static. Hence, reputational concerns do not affect the choice of sellers about the informational content of the reports they send. In the experiment, the games are repeated a few times. Thus, in principle, the sellers of information may benefit from creating a reputation for honesty in the Soft game. This makes the nonviability of information markets in the laboratory even more striking. The experimental results provide a negative reply to our motivating question. Despite being "theoretically" possible, markets for information do not develop with Soft information.

Having provided an answer to our main question, we also investigate the mechanism leading to this finding. In line with previous literature, we observe many truthful messages from sellers of information, even when sending a truthful message reduces the gains they can earn from their superior information. This favors the emergence of a well-functioning information market. A counteracting effect, however, operates in the opposite direction. Sellers of information who cannot profit from it often either lie or send uninformative messages.

The fact that some uninterested sellers are not sending informative messages is a novel finding, to the best of our knowledge. To understand this behavior, it is important to note the following. When a seller of information cannot profit directly from it and sends truthful reports, a receiver may benefit from it. Hence, his expected payoff could be higher 
than that of the sender. Thus, a possible explanation for the behavior we observe is that the seller is envious or nonprosocial. In that case, he may prefer to lie and thereby lower the payoff gained by the buyer of information. Of course, alternative explanations are possible. For example, a babbling equilibrium could prevail in the message part of the game: sellers could randomize their reports or send the same report regardless of the information they have. This would also lead to the collapse of the market for information.

To investigate the determinants of this behavior, we measure the social preferences of subjects playing the games. However, there is a low number of purchases of information, and thus messages sent, in the Soft game. This makes it quite hard to test the hypothesis that the low quality of information arises from envy motives or a lack of prosociality. In Cabrales et al. (2016), we analyze a sender-receiver game closely related to the message component of the Soft game. In the experimental evidence we obtain for that game, we find that social preferences can explain the anomalous, nontruthful behavior of senders. However, we cannot unambiguously conclude from this finding that the same is true in the situation considered here. The two games still exhibit some significant differences. We leave this question for future research.

The lack of truthfulness in the reports could contribute to the low participation in the market for information. However, we argue that this is not the only reason for the low level of activity in this market. This emerges from the experimental findings for a variant of the baseline treatment, which we call Uninterested. In that treatment, the sellers of information cannot profit from using the information directly. ${ }^{1}$ Hence, a conflict of interest between sellers and buyers of information never arises. Because of this, the seller has no direct benefit from misinforming the buyers of information. We find that the quality of information is indeed significantly higher than in the Soft treatment. Up to $92 \%$ of the reports are then truthful (instead of approximately only half of the reports in the Soft treatment). However, information sales are still rather low, very far below those in the most informative equilibrium and significantly below those in the Hard treatment. The results obtained for the Uninterested treatment are thus important. They suggest that the certainty of having accurate information compared to information whose quality is uncertain but still very likely to be accurate has very different implications for agents' willingness to purchase information. This is an important finding. Past theoretical

\footnotetext{
${ }^{1}$ We ran two variants of this treatment, labelled Uninterested-20 and Uninterested-10. See Section 4 and Appendix B for details.
} 
literature on information transmission, starting with Crawford and Sobel (1992), emphasizes that the alignment of interests between the sender and receiver is the key for the emergence of communication. We find that the certainty about the accuracy of information is more important.

\subsection{Literature}

First, we should mention the seminal work of Crawford and Sobel (1982) on strategic information transmission. They study how the alignment of preferences between sender and receiver affects information transmission (Sobel (2013) reviews the vast theoretical literature that followed). ${ }^{2}$ With respect to that paper (and the subsequent literature), we consider a different and richer game structure. This yields some novel results. In particular, the amount of information available to agents is endogenously determined. We also allow payments to be required for the receipt of messages. Crucially, the alignment of interests between senders and receivers is not commonly known. It depends on whether the sender can or cannot directly profit from the information acquired, and this is only privately known by the sender.

The experimental literature on information transmission has concentrated primarily on analyzing sender-receiver games à la Crawford and Sobel (1982). A first series of papers (e.g., Dickhaut, McCabe and Mukherji (1995), Blume et al. (1998, 2001), and Kawagoe and Takizawa (1999)) demonstrates that when the interests of the sender and receiver are perfectly aligned (the underlying game is one of common interest), play tends to converge to informative/separating equilibria, although other equilibria (babbling/pooling) exist. A more recent strand of the literature (see Sánchez-Pagés and Vorsatz (2007), Kawagoe and Takizawa (2005), Cai and Wang (2006), and Wang, Spezio and Camerer (2010)) finds more evidence of truth-telling than the most informative equilibrium in Crawford-Sobel would predict in games in which interests are not perfectly aligned, an outcome that can be explained by a truth-telling norm. ${ }^{3}$ While in our experiments we also find some evidence of aversion to lying, we also observe a substantial amount of deception/misinformation even when lying does not increase the senders' payoff but reduces that of the receivers.

\footnotetext{
${ }^{2}$ There is also a relevant theoretical literature that studies information transmission when agents may have a preference for telling the truth (see Kartik, Ottaviani and Squintani (2007) and Bolton, Freixas and Shapiro (2007)).

${ }^{3}$ This behavior could simply be due to pure lie aversion, which, as reported by López-Pérez and Spiegelman (2013), is a significant force behind honesty.
} 
The paper is organized as follows. The Soft and the Hard games and their equilibria are presented in Section 2, while Section 3 describes the experimental design and the results. Finally, some robustness checks of our findings are briefly presented in Section 4, together with some concluding remarks. The experimental instructions, together with the description of the findings for the Uninterested treatments and additional results, are collected in the Appendix, available online.

\section{The game and equilibria}

The main objective of this paper is to assess and compare the viability of information markets in the presence of soft and ofhard information. To this effect, we consider two simple variants of the model proposed in CG.

There is one object for sale. The object can be of one of 2 possible varieties, assumed to be equally likely ex ante. Let $v \in\{1,2\}$ be the true variety of the object. There are 3 potential buyers. Each buyer $i \in\{1,2,3\}$ has utility 200 for one variety $\theta_{i}$ and 100 for the other variety. The value of $\theta_{i}$ can be 1 or 2 with the same probability and is drawn independently across types at the beginning of the game; it is buyer i's private information and denotes his type. The object is allocated to buyers via a second-price auction.

We assume that, to begin with, no trader knows the variety of the object for sale. However, before the auction takes place, any buyer can learn the true variety of the object by paying a cost $c=20$. Any agent who pays this cost can then sell a report about the information learned. The utility of buyer $i$ is denoted by $\pi_{i}=\left(100+100 I_{v i}\right) I_{s i}-$ $20 I_{c i}-t_{i}$, where $I_{s i}$ is an indicator variable that takes the value 1 if buyer $i$ gains the object and 0 otherwise, $I_{v i}$ takes the value 1 if the variety of the object equals $i$ 's type and 0 otherwise, and $I_{c i}$ takes the value 1 if $i$ acquires information directly and 0 otherwise. Finally, $t_{i}$ is the sum of the payment made by player $i$ in the auction and of the net payment of the same player to purchase/sell information in the market for reports. An important feature of this environment is that, as we will explain below, the preferences of the seller and buyers of information are not always in conflict, but since types are privately known, it is also not common knowledge whether this is the case.

To be more precise, the timing of the game is as follows:

1. Each buyer decides, in a prespecified sequence, whether to pay $c$ to acquire information about the object or not. This decision to acquire information is observable by all agents. 
2. All the buyers who paid cost $c$ learn the true variety of the object, and then they simultaneously decide whether to sell a report and, if so, post its price $p_{i}$, thus becoming sellers of information.

3. All the buyers who did not acquire information in stage 1 decide, again in a prespecified sequence, whether to purchase a report from one or more of the agents selling information. These decisions are also commonly observed.

4. Any seller of information sends a (common) report to all the buyers who purchased information from him.

5. A second-price auction takes place among all buyers to allocate the object.

We consider two different specifications of this game, which differ by the nature of the information that is sold. In the first specification (Soft game), the report is unverifiable, a cheap-talk message; hence, the information sold is soft. The set of messages available to a seller of information is given by the set of possible varieties of the object plus one additional message. We will refer to this last message as the empty message, denoted by 0 . Thus, the set of messages is as follows: $M=\{0,1,2\}$.

In the second specification (Hard game), the seller must truthfully report the true variety of the object. In this case, what is sold is hard information.

We turn next to analyze the equilibria of these two games. Note that they differ only in stage 4 , when the seller of information may choose the content of the information in the Soft game, but not in the Hard game. Our aim is precisely to study the impact of this difference and the choice over the content of information transmitted on the viability of the information markets and the properties of the allocations that are obtained. To this end, we will focus on equilibria in which players use undominated strategies in the auction (we refer to them as truthful bidding strategies because each buyer makes a bid equal to his expected valuation for the object, conditional on his information).

We start with the Soft game. By a straightforward reformulation of the analysis in $C G$, we can show that an equilibrium with nontrivial information transmission exists. In that equilibrium, sellers of information always tell the truth whenever doing so is an agent's best response to the other players' strategies and beliefs (we refer to this as the informative equilibrium). Since the information sent in stage 4 is a cheap-talk report and babbling equilibria always exist in cheap-talk games (see Crawford and Sobel (1982)), the Soft game considered has multiple equilibria. 
In particular, in the informative equilibrium, sellers of information adopt the following message strategy:

$$
m_{i}=\left\{\begin{array}{l}
v \text { if } v \neq \theta_{i} \\
0 \text { if } v=\theta_{i}
\end{array}\right.
$$

where $m_{i}$ is the report issued by agent $i$. Therefore, agent $i$ is truthful about the variety of the object when this is different from his own type. However, when he likes the object, he sends the empty message.

To understand why this strategy could be optimal, it is useful to examine the nature of the possible conflict of interest between the seller and the buyers of information. When agent $i$ (the seller) learns that the true variety of the object is not the one he likes, the seller does not expect to gain from participating in the auction. This is true whatever the information the buyers have. His payoff (as specified in $\pi_{i}$ ) is then unaffected by the content of the report, and he is thus willing to tell the truth. On the other hand, in the event that the seller learns he likes the object, the seller would like to acquire the object in the auction and prefers then to send a report that lowers the expected valuation of the buyers. In that case, there is a conflict of interest, and agent $i$ would gain by sending a message that deceives buyers and induces them to make the lowest bid. Because message strategy (1) conveys some information and hence the bids of buyers of information depend on the message received, this is achieved by sending the empty message.

When sellers adopt the strategy in (1), the reports sent have positive informational content, and hence, we can show that in equilibrium, buyers agree to pay a positive price for them.

As we said, other equilibria in which reports are less informative also exist. In particular, babbling equilibria, where the message sent is independent of the true type of the object and hence the report is totally uninformative, always exist. For example, the message strategy can be given by:

$$
m_{i}=0 \text { for every } v \text {. }
$$

In this case, in equilibrium, buyers will not agree to pay a positive price for the reports.

\section{Proposition 1.}

A) An informative perfect Bayesian equilibrium of the Soft game described above exists. In that equilibrium, the sellers of information adopt the reporting strategy in equation (1), while buyers choose a truthful bidding strategy in the auction. Furthermore, one agent acquires information and 
always posts a price $p=12.5$ for a report, which one other agent accepts. The object goes either to the seller of information when he likes the object or, in the event that the seller does not like it, to the buyer of the report when he, in turn, does like it; the price paid is 150, in both cases. If neither of them likes it, the third agent acquires the object at a price of 100.

B) Another perfect Bayesian equilibrium of the Soft game also exists where the sellers of information adopt the reporting strategy in equation (2) while buyers choose a truthful bidding strategy in the auction. Furthermore, one agent acquires information, and no reports are sold. The object goes to this agent, if he likes it, at a price of 150. If the agent does not like it, one of the other agents acquires the object for a price of 150.

Note that in equilibrium A), the buyer of a report gains from it because it allows him to gain the object at a price of 150 when he likes it and the seller of information does not. In this event, the buyer pays 150 for an object with a value of 200 for him, a surplus of 50 . Since the event has probability $1 / 4$, a price of 12.5 is indeed the maximum he is willing to pay for such report.

The payoffs in the informative equilibrium, A), where the market for information is active, are as follows. The buyer who acquires information has an expected payoff of $\frac{1}{2}(200-150)+12.5-20=17.5$. The buyer who purchases a report has a payoff $\frac{1}{4}(200-150)-12.5=0$. The uninformed buyer has a payoff of $\frac{1}{8}(200-100)=$ 12.5 .

The payoffs in equilibrium B), where the market for information is inactive, are instead as follows. The informed buyer has an expected payoff of $\frac{1}{2}(200-150)-20=$ 5. The other buyers have an expected payoff of $\frac{1}{8}(200-150)+\frac{1}{8}(100-150)=0$.

In addition to the two equilibria characterized in Proposition 1, there is a continuum of other equilibria with intermediate levels of information conveyed by the seller's report. For instance, when the seller is not interested in the object, he can tell the truth with probability $q$ and send either of the other messages with equal probability $\frac{1}{2}(1-q)$, where $q \geq \frac{1}{3}$. The price of information in these equilibria ranges accordingly from 0 when $q=1 / 3$ to 12.5 when $q=1$. The truthful bids by the agents who buy information also vary with $q$ : when the buyer of information receives a message saying 
the object is of a type he likes, his expected valuation and hence the agent's truthful bid decrease with $\mathrm{q}$, from 200 when $q=0$ to 150 when $q=1 / 3$. When the buyer of information receives a message saying the object is of a type he does not like, his truthful bid increases with $\mathrm{q}$, from 100 when $q=0$ to 150 when $q=1 / 3{ }^{4}$

In spite of this multiplicity of equilibria, we should point out that the presence of an even very small cost of not telling the truth (as in Kartik (2009)), either from an intrinsic disutility or from fear of being caught and punished, would select the equilibrium in Proposition 1, point A.

In the Hard game, there is no issue regarding the quality of the information conveyed by the reports. Hence, the different incentives of the seller to transmit information when he likes or does not like the object affect his decision on whether or not to sell the information. We can show the following:

\section{Proposition 2. There exists a perfect Bayesian equilibrium of the Hard game} described above in which buyers choose a truthful bidding strategy in the auction. In this equilibrium, one agent acquires information, and when he does not like the object, the agent posts a price $p=25$ for a report, which one other agent accepts. If the agent likes the object, he does not post a price. The object goes to the seller of information if he likes it, and otherwise to the buyer of the report if he, in turn, likes it, at a price of 150. If neither of them likes it, the third agent gets the object at a price of 100.

Note that despite the high price at which information can be sold, the seller still prefers not to sell information in the event that he likes the object. Furthermore, there is

\footnotetext{
${ }^{4}$ Note that we would obtain very similar behavioral properties to those of the equilibria just described, with regard to information transmitted, prices of reports and auction bids, in the following situation: senders of information adopt a reporting strategy as in (1) but with mistakes, in the spirit of a quantal response equilibrium. Specifically, sellers follow the strategy specified in (1) with probability $1-\varepsilon$, and with probability $\varepsilon / 2$, they send one of the other two reports. The level of the truthful bids varies with $\varepsilon$ in the same way as we saw truthful bids vary with $\mathrm{q}$ in the equilibrium described in the main text (just replace $1-\varepsilon$ where we wrote $q$ ). The price of information also varies from 0 when $\varepsilon=2 / 3$ to 12.5 when $\varepsilon=0$. The main difference arises because, when the reporting strategy entails mistakes, as above, the sender sometimes does not send an empty message when he likes the object. This decreases his/her payoff from the auction in that event. While his expected payoff from the auction is 50/2 when the seller randomizes in the reports he sends when not interested in the object, in the presence of trembles his payoff is $\frac{1}{2}\left((1-\varepsilon) 50+\frac{\varepsilon}{2} 50+\frac{\varepsilon}{2}\left(200-\frac{400}{\varepsilon+2}\right)\right)$.
} 
no equilibrium where the seller always sells information, regardless of what the beliefs off the equilibrium path are. ${ }^{5}$

It is important to point out that in the equilibrium described in Proposition 2, both the allocation and the expected payoffs are the same as in the informative equilibrium of the Soft game described in Proposition 1, point A. Thus, in the environment considered, the soft or hard nature of the information should have no effect on either the market outcome or the performance of the market for information if the informative equilibrium obtains in the Soft game. Hence, according to the theory, a difference between hard and soft information would arise only if a different equilibrium were to prevail in the Soft game, an outcome that is not, however, robust to the possibility that individuals experience an arbitrarily small cost from not telling the truth. In what follows, by theoretical predictions, we refer to the case where the informative equilibrium obtains in the Soft game.

\section{The experiment and the results}

\subsection{Design of the experiment}

At the beginning of the experiment, subjects are divided into groups of three individuals. The subjects in any given group interact for 20 iterations of the game, and this feature is common information. Additionally, within each group of three subjects, each individual is randomly assigned a player position $(1,2$ or 3$)$ that remains fixed throughout the experiment.

We consider two main treatments (which we label Soft and Hard), where we implement the Soft and Hard games described in Section 2. Players are informed that, in each round, they will have the opportunity to buy an object by bidding in an auction. The object can be either green or orange (its color is randomly drawn at the beginning of the round with equal probability). Similarly, each player has a randomly assigned color for the round (also green or orange, with equal probability). The object has a value of 200 ECUs (experimental currency units) for a player if it is of his assigned color and of 100

\footnotetext{
${ }^{5}$ On the other hand, an equilibrium where the seller never sells information does exist, supported by the out-of-equilibrium belief that a sale comes from a seller who likes the object. Such an equilibrium, however, does not survive the intuitive criterion.
} 
ECUs otherwise. At the beginning of every round, each player is endowed with 250 ECUs and is informed of his assigned color but not of others' colors or of the color of the object.

In every round, there are five stages. In the first stage, each player decides whether to pay 20 ECUs to learn the color of the object. The three players in any group make this decision in sequence, with an order randomly drawn at the beginning and then held fixed through the experiment, and with each player knowing the decisions of his predecessors.

In the second and third stages, we have the market for reports. In the second stage, each player who paid to acquire the information in stage 1, after learning the true color of the object, decides whether to set a price for his report on the color of the object. The price can be any integer number of ECUs less than or equal to 20. All sellers of information set prices simultaneously. Then, in the third stage, those players who are still uninformed decide which of the reports, if any, they want to buy at the indicated price (each one of those players can buy at most one report). These decisions are again made in sequence, with each player knowing the choices of his predecessors.

In the fourth stage, the reports are issued. This is the only point where the two treatments differ. In the Soft treatment, any sender is free to choose from the following reports: "the object is orange", "the object is green" or "the object is orange or green". In the Hard treatment, the sender must truthfully report the color of the object.

Finally, in the fifth stage, the auction takes place. The three players simultaneously make their bids for the object. A bid can be any number of ECUs less than or equal to 250. The players know that the highest bidder will obtain the object, earning 200 ECUs if it is of his assigned color and 100 ECUs if it is not, and paying a price equal to the second-highest bid. ${ }^{6}$ The remaining bidders neither earn nor pay anything. Then, payoffs are realized.

At the end of each round, each player is informed of his payoff, the true color of the object, the bids made by each player, and the player who won the object together with the price he paid. At the end of the experiment, subjects are paid their payoffs from 4 randomly selected rounds at a conversion rate of $100 \mathrm{ECUs}=1$ euro.

We ran four sessions for each treatment at the laboratory of experimental economics of the University of Siena (LabSi) in December 2017. A total of 99 subjects (51 in Soft and 48 in Hard) participated in these sessions, providing a total of 33 groups

\footnotetext{
${ }^{6}$ In the event of a tie, the acquirer of the object is randomly selected from among the highest bidders. Note that in this case, the highest and second-highest bids coincide.
} 
(17 in Soft and 16 in Hard). The subjects were recruited from the LabSi pool of human subjects, primarily consisting of undergraduate students from the University of Siena. No subject was allowed to participate in more than one session. After subjects had read the instructions, an experimental administrator read the instructions aloud. Throughout the experiment, we ensured anonymity and effective isolation of subjects to minimize any interpersonal influences that could stimulate cooperation. The average duration of the sessions was 70 minutes (including the reading of instructions but excluding payment procedures). The experiment was computerized and conducted using the experimental software z-Tree (Fischbacher (2007)). The experimental instructions, translated into English, are reported in (online) Appendix A. Table 1 provides a summary of all our experiments and treatments.

Table 1. Experimental data

\begin{tabular}{lccc}
\hline Treatment & \# sessions & \# groups & \# subjects \\
\hline Soft & 4 & $17(4+4+4+5)$ & 51 \\
Hard & 4 & $16(4+4+4+4)$ & 48 \\
\hline
\end{tabular}

After the 20 rounds of play, in all sessions, we elicited the subjects' attitudes towards risk and social preferences. We used the risk test proposed by Charness and Gneezy (2010). Regarding social preferences, we followed the approach proposed by Bartling et al. (2009) to identify prosocial and envious attitudes (see online Appendix E for details).

There is one design feature that deserves an explanation. We have fixed groups, and even fixed positions within each group, for the iterations of the game considered in a session, unlike in the theoretical benchmark considered in Section 2, where the players interact once. We made these choices because this is a complicated experimental design from a cognitive perspective, and we wanted to maximize the probability that the players learned the best strategies to play the game. This becomes easier when players are playing against a single group of players in a fixed position than when they are playing against changing opponents and/or changing roles. Obviously, the procedure also has disadvantages. The most important is that the repetition of the game may create new equilibria, and thus the theoretical benchmark is less clear. However, the main new equilibria that may arise are those in which the amount of truth-telling increases because of reputational concerns. As we will see, the amount of truth-telling in our results is even 
smaller than in the informative equilibrium described in Proposition 1, point A. Additionally, the dynamic trends that appear in the data are easy to explain using simple learning heuristics, without resorting to complicated strategies in the repeated game.

In this experimental design, the comparison of the Hard and Soft treatments allows us to study whether the nature of the information transmitted makes a significant difference in terms of the viability of the market for information.

\subsection{Results}

In this section, we present the experimental results for the Soft and Hard treatments and compare them with the theoretical predictions reported in Section 2. Table 2 presents the results concerning the behavior of subjects in the auction in the two treatments. In the columns, we report the bids made in the first half (rounds 1 to 10) and the second half (rounds 11 to 20) of the experiment. In the rows, subjects are differentiated according to their available information: In the first two rows, we report the behavior of the informed players, i.e., those who acquired information directly. Specifically, we show their average bid when the color of the object coincided with their assigned color (Color - Yes) and when it differed (Color - No). The third row displays the average bid of the uninformed players (i.e., those who neither acquired information directly nor purchased a report). The last rows display the average bid of indirectly informed players (buyers of reports) when the report states that the color of the object coincided with their assigned color (Color - Yes), when it did not coincide (Color - No) and when the report said "the object is orange or green" (we refer to this as the 0 report). We also report the bids that would be made by subjects in the equilibrium characterized in Proposition 1, point A, for the Soft treatment and Proposition 2 for the Hard treatment, referring to these as [Predictions].

Comparing the bids between treatments both by period and by the type of information that the subjects have available, we do not find systematic significant differences (as shown by the reported results of the Mann-Whitney test and t-test). Furthermore, in both treatments, we observe a clear learning pattern. When we move from the first to the second half of the experiment, bids are increasing, and they are getting quite close to the theoretical predictions. This fact holds for all types of available information and both treatments. 
RESULT 1. The bidding behavior in the auction does not differ across treatments, and in the second half of the experiment, it is very close (on average) to the theoretical predictions.

Table 2. Average bids by treatment, type of player and block of 10 rounds

\begin{tabular}{|c|c|c|c|c|c|}
\hline & & \multicolumn{2}{|c|}{ Soft } & \multicolumn{2}{|c|}{ Hard } \\
\hline & Rounds & $1-10$ & $11-20$ & $1-10$ & $11-20$ \\
\hline \multirow{2}{*}{$\begin{array}{l}\text { Informed } \\
\text { players }\end{array}$} & Color-Yes [Prediction: 200] & 152.87 & 203.22 & $153.48 *$ & 200.87 \\
\hline & Color-No [Prediction: 100] & 91.75 & 116.51 & 93.05 & 120.12 \\
\hline $\begin{array}{l}\text { Uninformed } \\
\text { players }\end{array}$ & [Prediction: 150] & 115.81 & 145.22 & 112.21 & 143.58 \\
\hline \multirow{3}{*}{$\begin{array}{l}\text { Buyers of } \\
\text { report }\end{array}$} & $\begin{array}{l}\text { Content: Color - Yes } \\
\text { [Prediction: 200] }\end{array}$ & 135.06 & 180.14 & 142.57 & $206.80^{\wedge}$ \\
\hline & $\begin{array}{l}\text { Content: Color - No } \\
\text { [Prediction: 100] }\end{array}$ & 105.53 & 136.37 & 74.37 & 140.00 \\
\hline & $\begin{array}{l}\text { Content: } 0 \\
\text { [Prediction: 150] }\end{array}$ & 93.94 & 167.5 & N/A & $\mathrm{N} / \mathrm{A}$ \\
\hline
\end{tabular}

Soft vs. Hard: Mann-Whitney test significance at $* * * p<0.01,{ }^{* *} p<0.05, * p<0.1$

Soft vs. Hard: t-test significance at $\wedge \wedge \wedge p<0.01, \wedge \wedge p<0.05, \wedge p<0.1$

In Table 3, we present, for both treatments, the numbers and relative frequencies for the different choices that players could make regarding the acquisition of information: (i) to directly acquire information in the first stage (Informed), (ii) to buy a report in the third stage (Buy a report) and (iii) to remain uninformed (Uninformed). We again present the data separately for the first ten rounds and the second ten rounds of the experiment. According to the informative equilibrium of the Soft game described in Section 2, we should observe the same number for each of these choices: in each period, one player in the group should directly acquire information, one player should buy a report, and one player should remain uninformed. According to the equilibrium of the Hard game, in each period, one player in the group should directly acquire information, one player should remain uninformed, and the remaining player should either buy a report (in case the informed player is not interested in the object and, therefore, posts a price) or remain uninformed (otherwise).

In the first half of the experiment, in both treatments, the modal choice was acquiring the information directly, followed by the choice of remaining uninformed, with 
a low frequency of purchasing a report. However, the frequency of buying a report is significantly lower in the Soft treatment (9.61\%) than in the Hard treatment (19.79\%) at the $1 \%$ level (Mann-Whitney test), and the frequency of acquiring the information directly is considerably higher in the Soft treatment than in the Hard treatment $(65.29 \%$ and $49.79 \%$, respectively), with the difference being significant at the $1 \%$ level (MannWhitney test).

Table 3. Behavior in information markets in the Soft and Hard treatments - absolute number of observations and relative frequencies ( $\%$ over row total)

\begin{tabular}{|l|l|l|l|l|l|l|}
\hline \multirow{3}{*}{} & \multicolumn{3}{|c|}{ Rounds 1-10 } & \multicolumn{3}{c|}{ Rounds 11-20 } \\
\cline { 2 - 7 } & Uninformed & Informed & Buy a report & Uninformed & Informed & Buy a report \\
\hline \multirow{2}{*}{ Soft } & 128 & $\mathbf{3 3 3}$ & 49 & $\mathbf{2 5 6 \wedge \wedge}$ & $228^{\wedge}$ & $26^{\wedge \wedge}$ \\
& $(25.10)$ & $\mathbf{( 6 5 . 2 9 )}$ & $(9.61)$ & $\mathbf{( 5 0 . 2 0 )}$ & $(44.71)$ & $(5.10)$ \\
\hline \multirow{2}{*}{ Hard } & 146 & $\mathbf{2 3 9} * * *$ & $95^{* * *}$ & 177 & $\mathbf{2 1 2}$ & $91 * * *$ \\
& $(30.42)$ & $\mathbf{( 4 9 . 7 9 )}$ & $(19.79)$ & $(36.88)$ & $\mathbf{( 4 4 . 1 7 )}$ & $(18.96)$ \\
\hline
\end{tabular}

Soft vs. Hard: Mann-Whitney test significance at *** $p<0.01,{ }^{* *} p<0.05,{ }^{*} p<0.1$

Periods 1-10 vs. 11-20: Signed-rank test significance at $\wedge \wedge \wedge p<0.01, \wedge \wedge p<0.05, \wedge p<0.1$

In the second half of the experiment, we find that differences across treatments increase. First, we observe that, whereas the modal choice for the Hard treatment is again to acquire the information directly, in the Soft treatment, it becomes to remain uninformed. Moreover, we find that in the Soft treatment, the frequency with which reports are purchased is markedly reduced (from $9.61 \%$ in the first half of the experiment to $5.10 \%$ in the second half, the difference being significant at the $5 \%$ level in the signedrank tests), while in the Hard treatment, it remains fairly constant between both halves (19.79\% and $18.96 \%$, respectively). Hence, the observed difference across treatments of the level of activity in the market for reports increases in the second half of the experiment. Indeed, in the Soft treatment, we find that the market for reports progressively collapses. ${ }^{7}$ Furthermore, when comparing the first to the second half of the experiment, we find systematic and significant differences only for the Soft treatment, so the evolution of information acquisition is different across treatments. Overall, these results show that the market for reports in the Soft treatment is systematically smaller with respect to the Hard treatment and ultimately collapses.

\footnotetext{
${ }^{7}$ We observe a negative trend in the frequency of purchases of reports, which decreases from almost $10 \%$ in the first 10 periods to slightly above $6 \%$ in periods $11-15$ and below $4 \%$ in the last 5 periods.
} 
It is important to note in this context that the market for reports in the Hard treatment works even slightly better than in the equilibrium benchmark: we have almost $20 \%$ of agents buying a report, whereas in equilibrium we have $16.6 \%$ (recall that, in equilibrium, the informed player posts a price only half of the time - when he is not interested in the object).

\section{RESULT 2. In contrast to the theoretical prediction, in the Hard treatment, we observe a larger market for reports than in the Soft treatment. Moreover, in the Soft treatment, the market for information shrinks over time, whereas it remains stable in the Hard treatment.}

This result is one of the most important take-home messages from our paper. The difference between the two treatments is exclusively the "hardness" of information. According to the theory, this need not make a difference, as in the main equilibrium considered for the two games, the level of activity in the market for information, and in particular the amount of information transmitted, is the same in both. However, the data show that this market is deeper and more robust in the Hard than in the Soft treatment.

To understand the reasons for this collapse of the market for reports in the Soft treatment, one is naturally led to relate it to the informational content of the reports sent. In Table 4, we present the reports sent, distinguishing the case in which the seller is interested in the object (the object is of his assigned color) and the case in which he is not interested. ${ }^{8}$ We observe that the (average) frequency of truthful reports is $52.11 \%$, very close to the theoretical prediction reported in Proposition 1, point A (50\%). However, the distribution of truthful reports between the case in which the sender is uninterested in the object and that in which he is interested is quite different from the predicted distribution.

In the equilibrium for the Soft game described in Proposition 1, point A, sellers of information are always truthful when they cannot benefit from lying. Hence, uninterested sellers send a truthful report (i.e., reveal the color of the object), while interested sellers send a 0 report. The prediction is thus that all truthful messages occur when the sender is uninterested. In the experimental evidence, we observe a significant departure from such behavior: while the modal choice of uninterested sellers $(43.75 \%)$ is indeed to reveal the

\footnotetext{
${ }^{8}$ In Figure F1 in Appendix F, we present the distribution of groups by frequency of truthful reports in the Soft treatment. Furthermore, in Table F2 we report the distribution of the type of received reports by blocks of periods.
} 
true color, there is also a significant fraction of 0-reports $(25.00 \%)$ and even false ones (31.25\%). At the same time, interested sellers send truthful reports with a very high frequency $(58.97 \%)$. This has a significant effect on the value a receiver obtains from the purchase of information (a truthful message received when the sender is interested in the object means that the receiver will face aggressive bidding from the sender in the auction, as confirmed by the evidence reported in Table 2). ${ }^{9}$

Table 4. Content of the report sent by type of seller (interested in the object or uninterested) in the Soft treatment - absolute number of observations and relative frequencies $(\%$ over row total)

\begin{tabular}{|c|ccc|c|}
\hline \multicolumn{1}{|c}{ Seller } & O report & False report & \multicolumn{1}{c|}{ Truthful report } & Total \\
\hline \multirow{2}{*}{ Uninterested } & 8 & 10 & $\mathbf{1 4}$ & 32 \\
& $(25.00)$ & $(31.25)$ & $\mathbf{( 4 3 . 7 5 )}$ & $(100)$ \\
Interested & 9 & 7 & $\mathbf{2 3}$ & 39 \\
& $(23.08)$ & $(17.95)$ & $\mathbf{( 5 8 . 9 7 )}$ & $(100)$ \\
Total & 17 & 17 & $\mathbf{3 7}$ & 71 \\
& $(23.94)$ & $(23.94)$ & $\mathbf{( 5 2 . 1 1 )}$ & $(100)$ \\
\hline
\end{tabular}

The observed reporting choices of sellers of information should be assessed in light of the response by buyers of information in terms of their behavior in the auction. As shown in Table 2, buyers attribute some (though not full) informative value to a report specifying one color of the object and less value to a 0 report. It may also be claimed that the observed reporting behavior exhibits some features of either the babbling equilibrium or one of the other equilibria described in Section 2 with intermediate degrees of information transmitted, especially when the seller of reports is not interested in the object. However, the modal choice of truthful reporting when the seller of reports is interested in the object is not compatible with these equilibria. ${ }^{10}$

RESULT 3. In the Soft treatment, the information conveyed in the reports is very noisy and differs sharply from the main equilibrium predictions. Uninterested sellers send truthful reports in less than half of the cases, and there is an (unpredicted) considerable share of false messages.

\footnotetext{
${ }^{9}$ See Figure F4 in Appendix F for an analysis of the relationship between the size of the market for reports and the rate of truthful reporting at the group level in the Soft treatment. We do not find a significant correlation.

${ }^{10}$ Relatedly, in Table F3 in Appendix F, we report the average bids in the auction by buyers of reports, categorizing them into groups by (average) high and low quality of reports.
} 
To gain some understanding of the observed pattern of activity in the market for reports and, in particular, of the deviations from the theoretical predictions, in the following, we examine the observed behavior in the parts of the game that determine supply and demand in this market. We therefore study (i) the behavior of informed agents regarding whether to post a price or not (i.e., whether to try to sell information), (ii) the asking prices for the reports, and (iii) the prices that are accepted by the buyers of reports. To assess the rationale for these decisions, we also analyze the earnings obtained by agents in the whole game for the different types of the information that they have.

In Table 5, we report the data regarding the decision of informed agents on whether to post a price. We also report the corresponding behavior in the Hard treatment.

Table 5. Decision to post a price in the market for reports: relative frequency and total number of potential sellers

\begin{tabular}{|l|l|l|}
\hline & Uninterested & Interested \\
\hline \multirow{2}{*}{ Soft } & $0.860^{*}$ & $0.832^{* * *}$ \\
& 193 & 185 \\
\hline \multirow{2}{*}{ Hard } & 0.804 & $0.635^{\wedge \wedge \wedge}$ \\
& 209 & 203 \\
\hline
\end{tabular}

Soft vs. Hard: Mann-Whitney test significance at $* * * p<0.01,{ }^{* *} p<0.05, * p<0.1$ Uninterested vs. Interested: Signed-rank test significance at $\wedge^{\wedge \wedge} p<0.01, \wedge \wedge p<0.05, \wedge p<0.1$

We find significant differences both between and within treatments: interested subjects in the Hard treatment post a price at a frequency that is considerably lower than the frequency at which uninterested subjects post a price in the same treatment. They also post a price at much lower frequency than interested subjects in the Soft treatment. Note that this evidence is in line with the theoretical predictions and could be explained by the fact that the only way for interested subjects to avoid revealing information in the Hard treatment is to not post a price.

On the other hand, we observe that all subjects (either interested or not) in the Soft treatment, as well as uninterested subjects in the Hard treatment, post a price at a slightly lower rate than predicted $(100 \%)$. It is important to point out that, in relative terms, the drop in price posting decisions is not larger but actually smaller in the Soft treatment than in the Hard treatment. The presence of a nontrivial fraction of uninterested sellers who choose not to post a price in the Hard treatment is particularly difficult to explain, taking into account the observed willingness to purchase shown by buyers in that treatment. The same can be said of the fact that more than half of the interested sellers in this treatment 
choose to post a price, though the sale of information leads them to face higher competition in the auction (and the theory predicts no sale in such a case). ${ }^{11}$

Next, we examine the level of the prices posted for the sale of reports and how they evolve throughout the experiment. These prices reflect the sellers' perception of the willingness to pay of buyers for the information conveyed in the reports (as well as, in the Hard treatment, the sellers' willingness to share the information they acquired). Table 6 presents the average price posted in each round (if more than one price is posted in a round, the minimum price). This is done separately for the first and last ten rounds and according to whether the seller is interested or uninterested in the object.

Table 6. Minimum asking price in the market for reports

\begin{tabular}{|l|l|l|}
\hline & \multicolumn{1}{|c|}{ Rounds 1-10 } & \multicolumn{1}{c|}{ Rounds 11-20 } \\
\hline Soft & 8.23 & $6.49^{\wedge \wedge}$ \\
\hline Hard & $11.29^{* * *}$ & $11.40^{* * *}$ \\
\hline & \multicolumn{1}{|c|}{ Uninterested } & \multicolumn{1}{c|}{ Interested } \\
\hline Soft & $7.67 \quad 11.33^{* * *}$ & 7.30 \\
\hline Hard & $11.40^{* * *}$ \\
\hline
\end{tabular}

Soft vs. Hard: Mann-Whitney test significance at $* * * p<0.01, * * p<0.05, * p<0.1$

Rounds $1-10$ vs. $11-20$ and Uninterested vs. Interested: Signed-rank test significance at $\wedge \wedge \wedge p<0.01, \wedge \wedge p<0.05, \wedge p<0.1$

We observe a strongly significant difference across treatments. The posted prices are higher in the Hard treatment both when we disaggregate by blocks of periods and when we disaggregate by the seller's interest in the object, and the difference is statistically significant. To assess this finding, we should take into account that the theoretical prediction of the price in the Hard treatment (when the seller is uninterested) is 25 , double that in the Soft treatment. At the same time, as already noted, we observe in the experiment that sellers also post prices quite often when they are interested, and this reduces the value of the information sold. ${ }^{12}$ The most remarkable finding is that in the second part of the experiment, the posted prices are significantly smaller in the Soft treatment relative to those in the first part, while in the Hard treatment, they remain roughly constant. The decline in posted prices in the Soft treatment is presumably due to

\footnotetext{
${ }^{11}$ In Table F5 in Appendix F, we report, for the Hard treatment, the frequencies of groups by number of acquirers of information, and the frequencies of the decisions to post a price. Furthermore, in Table F6, we report the frequencies of buyers of reports by number of acquirers of information in the group. See then Table D1 in Appendix D for an econometric analysis of the determinants of this behavior.

${ }^{12}$ In fact, if sellers in the Hard treatment were to always post a price, the theoretical value of the information would be half, equal to 12.5 , which is close to the average observed posted price.
} 
the experience of difficulty in selling, which induces sellers to revise their perception of buyers' willingness to pay. Additionally, we note that posted prices do not depend in a significant way on whether the subject is interested in the object or not.

Finally, in Table 7, we present the prices accepted by buyers and the acceptance rate (that is, the ratio between the number of accepted prices and the number of posted prices, or equivalently, the fraction of sellers succeeding in selling at least one report), again for the first and second blocks of ten rounds. These prices reflect the perception of buyers of the value of being informed and, in the Soft treatment, their perception of the quality of the information transmitted. Hence, they together capture the demand side of the market. Comparing the findings in Tables 6 and 7 allows us to relate the level of activity in the market for reports in the two treatments to the presence of possible gaps between the price at which informed agents are willing to sell information and the price at which uninformed agents are willing to buy.

We see from Table 7 that the Hard treatment displays significantly higher levels of accepted prices. Additionally, and more importantly, acceptance rates are higher in the Hard treatment.

Table 7. Accepted price and acceptance rate in the market for reports

\begin{tabular}{|l|l|l|l|}
\hline & & Rounds 1-10 & Rounds 11-20 \\
\hline \multirow{2}{*}{ Accepted Price } & Soft & 8.35 & 4.96 \\
\cline { 2 - 4 } & Hard & $11.19^{*}$ & $11.40^{* * *}$ \\
\hline \multirow{2}{*}{ Acceptance Rate } & Soft & 0.24 & 0.19 \\
\cline { 2 - 4 } & Hard & $0.55^{* * *}$ & $0.56^{* * *}$ \\
\hline
\end{tabular}

Soft vs. Hard: Mann-Whitney test significance at *** $p<0.01,{ }^{* *} p<0.05, * p<0.1$

Rounds 1-10 vs. 11-20: Signed-rank test significance at $\wedge^{\wedge \wedge} p<0.01, \wedge \wedge p<0.05, \wedge p<0.1$

These findings are evidence of a lower level of demand for information in the Soft treatment. In spite of the observed decline in Table 6 in the level of the prices posted by sellers in the Soft treatment, the table above shows that the acceptance rate does not increase over time; if anything it appears to slightly decrease. This is clearly related to the significantly lower level of information contained in the reports in the Soft treatment, as observed in Table 4. This decline reflects the fact that over time, buyers of information realize reports are quite noisy and hence are willing to pay less for them. Thus, our results suggest that in the Soft treatment, there is a larger gap between the price at which sellers are willing to (or conjecture they can) sell and the price that buyers are willing to pay. 
It is of interest to relate the observed pattern of accepted prices to the actual information contained in the reports purchased and hence to the actual benefit buyers receive from purchasing a report. The higher (average) prices in the Hard treatment reflect the higher level of information conveyed in the reports in that case. In contrast, although the prices in the Soft treatment are below the equilibrium prediction reported in Proposition 1, point A, they may still be perceived as being too high relative to the value of the reports, given the much larger level of noise present in the content of the reports with respect to the equilibrium prediction (as reported in Table 4). ${ }^{13}$ The former analysis reported in Table 5 suggests that the collapse of the market in the Soft treatment cannot be attributed to a shortage of decisions to post prices. Hence, the findings of Tables 6 and 7 on the pattern of prices posted over time and the transactions clearly indicate that such a collapse of the market can be attributed to the buyers' low willingness to pay for information, given the noise in the information conveyed, and the sellers' misperception of buyers' demand.

Finally, in Table 8, we analyze the subjects' earnings in the two treatments, distinguishing by the type of information available to the subjects and by the time in the experiment (first or second block of ten rounds in the experiment). ${ }^{14}$ In both treatments, we find that earnings decline significantly over time for informed players. In addition, we do not find systematically significant differences in payoffs for any given role across treatments.

Table 8. Average earnings by treatment, type of available information and rounds

\begin{tabular}{|l|l|l|}
\hline & \multicolumn{2}{|c|}{ Soft treatment } \\
\hline & Rounds 1-10 & Rounds 11-20 \\
\hline Uninformed & 256.60 & 251.63 \\
\hline Informed & $246.85^{*}$ & $240.26^{\wedge \wedge \wedge}$ \\
\hline Buyers of reports & 245.90 & 250.54 \\
\hline & \multicolumn{2}{|c|}{ Hard treatment } \\
\hline & Rounds 1-10 & Rounds 11-20 \\
\hline Uninformed & 259.23 & 246.69 \\
\hline Informed & 259.33 & $240.35^{\wedge \wedge \wedge}$ \\
\hline Buyers of reports & 252.61 & 242.54 \\
\hline
\end{tabular}

Soft vs. Hard: Mann-Whitney test significance at ${ }^{* * *} p<0.01,{ }^{* *} p<0.05,{ }^{*} p<0.1$

\footnotetext{
${ }^{13}$ We further explore the effects of the level of prices posted on the subjects' decisions to buy reports in the econometric analysis reported in Table D1 in Appendix D. This analysis shows that higher prices significantly reduce the purchases of reports in both treatments.

${ }^{14}$ See Table F1 in Appendix F for a description of the (gross) earnings in the auction.
} 
Rounds 1-10 vs. 11-20: Signed-rank test significance at ${ }^{\wedge \wedge \wedge} p<0.01, \wedge \wedge p<0.05, \wedge p<0.1$

If we then compare the differences in earnings between types of players (signedrank tests available upon request), we do not find any significant difference in the first part of the experiment in either the Soft treatment or in the Hard treatment. On the other hand, in rounds 11-20, we find that, in the Soft treatment, the earnings of informed players are significantly lower than those of uninformed players ( $1 \%$ level) and those of buyers of reports (5\% level); in the Hard treatment, the earnings of informed players are also significantly lower than those of uninformed players (5\% level). No other differences are significant.

These findings could seem puzzling considering the predictions of theory. In all the equilibria we characterized for the Soft and Hard games, it is the informed player who gets the highest payoff. However, we should point out that the subjects who acquire information in the Soft treatment are very rarely able to sell it. Therefore, they bear the cost of the acquisition of information and the benefits from the superior information in the auction and from the sale of reports are often not sufficient to cover such cost . This can easily explain the small negative difference we observed in their payoffs relative to the ones of players in other roles. In the Hard treatment, the puzzle can be explained because the informed players sell information too often when they are interested in the object, relative to the equilibrium predictions, and by so doing they increase the competition in the auction. Importantly, this also reduces total surplus in the Hard treatment, even though the market for information remains viable in that case, as the surplus is "bid away" in the auction and goes instead to the owner of the object. ${ }^{15}$

To try to shed additional light on the results, we perform a regression analysis in which we relate the behavior in the information market to past behavior by other players in the same market and the risk and social preferences of the participants. The two main takeaways of this analysis are the following (see Appendix D for all details). The first is that the social preferences of subjects appear to be a driver of the observed departures from equilibrium behavior in the decision to post a price for information in the Hard

\footnotetext{
${ }^{15}$ See Table F7 in Appendix F for a description of the behavior in the information market by treatment and player position.
} 
treatment. The other is that the experience of information that is too noisy in the reports in the Soft treatment contributes to driving buyers out of the market in that treatment.

\section{Discussion}

We have established with the Hard and Soft treatments that the nature of the information that is transmitted makes a significant difference for the viability of a market for information. We have also shown that the source of this outcome is a steep decrease in the willingness to pay for information in the Soft relative to the High treatment. We now deepen the analysis by showing that the reason for this outcome has more to do with certainty vs. uncertainty over the quality of information transmitted than with the alignment of preferences, as previous theoretical and experimental literature would suggest.

To this end, we also run two other treatments, labeled Uninterested-20 and Uninterested-10. With respect to the baseline of the Soft treatment, in these two treatments, we add a fourth player (player 0), who does not participate in the auction (he is uninterested in the object) and is the only player allowed to sell reports. In this case, the seller of information (player 0) can still lie and send noisy information in her report, but unlike in the Soft treatment, she cannot gain any material benefit from doing so, and this fact is common knowledge. The difference between these two additional treatments lies in the cost to player 0 of acquiring information: while in treatment Uninterested-20 player 0 has the same cost (of 20) of acquiring information as that of the other players, in treatment Uninterested-10, player 0 has a lower cost (of 10) of acquiring information.

The comparison of these two additional treatments with the previous ones allows us to investigate the role played by the presence of a conflict of interest between buyers and sellers of reports in the collapse of the market for reports.

A detailed description of the results for the Uninterested-10 and Uninterested-20 treatments is reported in Appendix B. Here, we should first highlight the fact that, as we observed in the Soft treatment, the market for information also turns out to be very small in these two additional treatments. This issue suggests that the conflict of interest is not the only determinant of market failure. Indeed, in periods 11-20, the proportion of players buying a report is $9.7 \%$ in Uninterested-20 and $14.24 \%$ in Uninterested-10. The difference between the two treatments is statistically significant, but in both cases, the amounts are very far below the theoretical benchmark (66.6\%; see Appendix B). Again, 
the low level of activity cannot be attributed to a low number of subjects attempting to sell information (in the last ten rounds, the frequency of uninterested player 1 trying to sell a report is $40.83 \%$ in Uninterested-20 and $81 \%$ in Uninterested-10).

This low demand for reports is important per se but even more so in conjunction with the fact that the quality of information is now quite good. We find that $84.06 \%$ of the reports are truthful in Uninterested-20 and 91.86\% in Uninterested-10. Therefore, the reason for the lack of trust in reports cannot be that the quality of information is poor. Nor are the prices for information particularly high. In the last 10 rounds, the posted prices are, on average, equal to 13.54 in Uninterested-20 and to 12.39 in Uninterested-10. The latter value is, in fact, not far from the theoretical prediction. This leads to an interesting observation. In the Hard treatment (where the quality of information is certain), many buyers are willing to purchase information at prices close to the above.

In the Uninterested treatments, especially in Uninterested-10, the quality of information turns out to be very high, though not perfect; nevertheless, the purchases made are significantly lower than the theoretical values. ${ }^{16}$ Thus, it seems that even a small amount of uncertainty about information quality can have large effects on information markets. ${ }^{17}$ This might be a potential insight for policy. If small amounts of misinformation can lead to a collapse in the market for information, the externalities caused by, for instance, false advertising might be higher than we thought. Regulators are, of course, aware of the harm of false advertising. ${ }^{18}$ Our research provides additional theoretical and empirical foundations for such concerns. Similarly, our findings also suggest that the provisions prescribing firewalls between analysts and traders present in many

\footnotetext{
${ }^{16}$ See Tables B2 and B4 in Appendix B.

${ }^{17}$ This is reminiscent of the findings in Charness et al (2014) in a network setup. In that experiment, when players knew the network with certainty, they were able to coordinate on the efficient equilibrium, but when there was a minimal amount of uncertainty they coordinated on the inefficient (but more secure) equilibrium.

${ }^{18}$ See, e.g., https://europa.eu/youreurope/citizens/consumers/unfair-treatment/unfair-commercial-

practices/index_en.htm for the EU, https://www.ftc.gov/news-events/media-resources/truth-advertising for the US or https://www.accc.gov.au/consumers/advertising-promotions/false-or-misleading-claims for Australia.
} 
regulations ${ }^{19}$ may not be that effective in sustaining well-functioning markets for information.

To test the robustness of the observed results (primarily those concerning the market for reports), we run an additional treatment, denoted Base. ${ }^{20}$ The Base treatment is very similar to the Soft treatment, but with one main difference: subjects that acquire the information post prices for reports prior to knowing whether they are interested in the object or not (that is, they learn the color of the object only before deciding the content of the report). ${ }^{21}$ We consider this specification because (i) it directly implements the theoretical model proposed in $C G$ and (ii) it allows us to see whether the collapse in the market for reports observed in the Soft treatment depends on the possible presence of a signaling component in the sellers' decision to sell information (muted in the Base treatment by the different assumption regarding the timing of sellers' decisions described above).

We show in Appendix C (Tables C1-C3) that the main features of the market for reports that we observed in the Base treatment are quite similar to those obtained for the Soft treatment. We also find that in this case, the market for reports collapses, with a negative trend in the number of reports sold over time and with almost no activity in the market for reports in the last rounds. Furthermore, the informational content of messages in the Base treatment is very poor, as in the Soft treatment, suggesting that this is again the key factor driving the failure of the market for reports. The evolution of asked and accepted prices during the experiment is also very similar to that observed for the Soft treatment.

\section{Conclusion}

To sum up, in this paper, we experimentally study the viability of markets for information where the information transmitted is soft, that is, transmitted via cheap-talk

\footnotetext{
${ }^{19}$ Section 501 of Title V in the Sarbanes-Oxley Act (significantly entitled 'Analysts' conflicts of interest') requires financial firms to establish specific safeguards to ensure the independence and separation of analysts from traders.

${ }^{20}$ We run 4 sessions for a total of 48 subjects (16 groups) that play 20 rounds of the game.

${ }^{21} \mathrm{We}$ also use a strategy method for the final auction.
} 
reports. In this environment, the game played by agents features equilibria with and without information transmission, and hence, an empirical assessment of the viability of information transmission seems necessary. Furthermore, previous results in the experimental literature on cheap-talk games suggest that subjects in the lab may tell the truth even when theory predicts that reports should be uninformative. To assess the role played by the soft nature of the information transmitted, we compare the experimental results for the game where messages can be false or uninformative with those for an analogous game where only hard information can be transmitted; that is, messages need to be true.

We find that in the laboratory, far fewer reports are sold in the game with soft information than in the game with hard information. We observe that some agents do indeed tell the truth when their monetary payoffs could be increased by sending deceptive reports. However, a novel finding in our experiment is that some agents lie when doing so does not increase their monetary payoff. This deceptive behavior and, more generally, the uncertainty generated by the possible presence of noise in transmitted information is one of the main reasons for the collapse of the market for information.

Our results for the Uninterested treatments allow us to disentangle the role of the actual noise present in reports from that of the possible presence of noise. However, further research along these lines would be very helpful to shed light on the problem at hand. For instance, an open question to investigate is to better understand why subjects send false or uninformative messages in cases in which there is an absence of a conflict of interest (e.g., false/empty reports sent by uninterested sellers in the Soft treatment) or, likewise, why some uninterested players do not post prices in the Hard treatment.

Our paper provides additional empirical support for existing regulatory policies in various areas. For example, our research shows that the alignment of interest between buyers and sellers of information is not sufficient to enable a well-functioning market for information. Hence, it is unclear whether firewalls between analysts and traders are enough to foster markets for information. Another application involves regulatory norms concerning truth in advertising. Even though markets for information are pervasive in reality, the fragility of this market in our experiments suggests that we should not take their existence for granted. Our results tell us that the absence of a conflict of interest between senders and receivers and/or a natural tendency toward truth-telling may not be enough for the survival of these markets. In our setting, senders of information can even 
construct reputations, but this is also not enough. Thus, our findings lead us to think that we need further research to determine the reasons for the survival of information markets in reality. For example, there may be a role for third-party certification (Lizzeri (1999)) or even government intervention to enforce accuracy in information transmission (Arrow (1963), Haas-Wilson (2001)). 


\section{References}

Alonso, R., Dessein, W., \& Matouschek, N. (2008). When does coordination require centralization? The American Economic Review, 98(1), 145-179.

Arrow, K. J. (1963). Uncertainty and the welfare economics of medical care. The American economic review, 53(5), 941-973.

Bartling, B., Fehr, E., Maréchal, M. A., \& Schunk, D. (2009). Egalitarianism and competitiveness. The American Economic Review, 99(2), 93-98.

Berry, S. T. (1992). Estimation of a Model of Entry in the Airline Industry. Econometrica, 889-917.

Blume, A., DeJong, D. V., Kim, Y. G., \& Sprinkle, G. B. (1998). Experimental evidence on the evolution of meaning of messages in sender-receiver games. American Economic Review, 1323-1340.

Blume, A., DeJong, D. V., Kim, Y. G., \& Sprinkle, G. B. (2001). Evolution of communication with partial common interest. Games and Economic Behavior, 37(1), 79-120.

Bolton, P., Freixas, X., \& Shapiro, J. (2007). Conflicts of interest, information provision, and competition in the financial services industry. Journal of Financial Economics, 85(2), 297-330.

Brandts, J., \& Charness, G. (2003). Truth or consequences: An experiment. Management Science, 49(1), 116-130.

Cabrales, A., Feri, F., Gottardi, P., \& Meléndez-Jiménez, M. A. (2016). Can there be a market for cheap-talk information? Some experimental evidence. CEPR Discussion Papers 11206, C.E.P.R. Discussion Papers.

Cabrales, A., \& Gottardi, P. (2014). Markets for information: Of inefficient firewalls and efficient monopolies. Games and Economic Behavior, 83(1), 24-44.

Cai, H., \& Wang, J. T. Y. (2006). Overcommunication in strategic information transmission games. Games and Economic Behavior, 56(1), 7-36.

Charness, G., \& Dufwenberg, M. (2006). Promises and partnership. Econometrica, 74(6), 1579-1601.

Charness, G., Feri, F., Meléndez-Jiménez, M. A., \& Sutter, M. (2014). Experimental games on networks: Underpinnings of behavior and equilibrium selection. Econometrica, 82(5), 1615-1670.

Charness, G., \& Gneezy, U. (2010). Portfolio choice and risk attitudes: An experiment. Economic Inquiry, 48(1), 133-146.

Costa-Gomes, M., Crawford, V. P., \& Broseta, B. (2001). Cognition and behavior in normal-form games: An experimental study. Econometrica, 69(5), 1193-1235.

Crawford, V. P., \& Sobel, J. (1982). Strategic information transmission. Econometrica, 50(6), 1431-1451.

Dempster, A. P., Laird, N. M., \& Rubin, D. B. (1977). Maximum likelihood from incomplete data via the EM algorithm. Journal of the Royal Statistical Society. Series B (Methodological), 39(1), 1-38.

Dickhaut, J. W., McCabe, K. A., \& Mukherji, A. (1995). An experimental study of strategic information transmission. Economic Theory, 6(3), 389-403.

Erev, I., \& Rapoport, A. (1998). Coordination, "magic," and reinforcement learning in a market entry game. Games and Economic Behavior, 23(2), 146-175. 
Ericson, R., \& Pakes, A. (1995). Markov-perfect industry dynamics: A framework for empirical work. The Review of Economic Studies, 62(1), 53-82.

Fehr, E., Glätzle-Rützler, D., \& Sutter, M. (2013). The development of egalitarianism, altruism, spite and parochialism in childhood and adolescence. European Economic Review, 64(C), 369-383.

Fischbacher, U. (2007). z-Tree: Zurich toolbox for ready-made economic experiments. Experimental Economics, 10(2), 171-178.

Garicano, L. (2000). Hierarchies and the organization of knowledge in production. Journal of Political Economy, 108(5), 874-904.

Gneezy, U. (2005). Deception: The role of consequences. The American Economic Review, 95(1), 384-394.

Haas-Wilson, D. (2001). Arrow and the information market failure in health care: The changing content and sources of health care information. Journal of Health Politics, Policy and Law, 26(5), 1031-1044.

Hurkens, S., \& Kartik, N. (2009). Would I lie to you? On social preferences and lying aversion. Experimental Economics, 12(2), 180-192.

Lizzeri, A. (1999). Information revelation and certification intermediaries. The RAND Journal of Economics, 30(2), 214-231.

López-Pérez, R., \& Spiegelman, E. (2013). Why do people tell the truth? Experimental evidence for pure lie aversion. Experimental Economics, 16(3), 233-247.

Kartik, N. (2009). Strategic communication with lying costs. The Review of Economic Studies, 76(4), 1359-1395.

Kartik, N., Ottaviani, M., \& Squintani, F. (2007). Credulity, lies, and costly talk. Journal of Economic Theory, 134(1), 93-116.

Kawagoe, T., \& Takizawa, H. (1999). Instability of babbling equilibrium in cheap talk games. Saitama University.

Kawagoe, T., \& Takizawa, H. (2005). Why lying pays: Truth bias in the communication with conflicting interests. Available at SSRN 691641.

Morgan, J., Steiglitz, K., \& Reis, G. (2003). The spite motive and equilibrium behavior in auctions. Contributions in Economic Analysis \& Policy, 2(1), Art. 5.

Sánchez-Pagés, S., \& Vorsatz, M. (2007). An experimental study of truth-telling in a sender-receiver game. Games and Economic Behavior, 61(1), 86-112.

Sobel, J. (2013). Giving and receiving advice, in Advances in Economics and Econometrics, D. Acemoglu, M. Arellano, and E. Dekel (eds.).

Sutter, M. (2009). Deception through telling the truth?! Experimental evidence from individuals and teams. The Economic Journal, 119(534), 47-60.

Wang, J. T. Y., Spezio, M., \& Camerer, C. F. (2010). Pinocchio's Pupil: Using eyetracking and pupil dilation to understand truth telling and deception in senderreceiver games. American Economic Review, 100(3), 984-1007. 


\section{ONLINE APPENDIX}

\section{A) EXPERIMENT INSTRUCTIONS}

\section{A.1 Experiment instructions for the Soft treatment ${ }^{22}$}

The aim of this experiment is to study how individuals make decisions in certain contexts. The instructions are simple. If you follow them carefully you will earn a nonnegligible amount of money in cash (euros) at the end of the experiment. During the experiment, your earnings will be in ECUs (experimental currency units). Individual payments will remain private, as nobody will know the other participants' payments. Any communication among you is strictly forbidden and will result in immediate exclusion from the experiment.

1. The experiment consists of 20 rounds. You will be randomly assigned to a group of 3 participants. This group is determined randomly at the beginning of the experiment and remains the same for all rounds. Moreover, you will be randomly assigned a player number within your group: you will be either player 1, player 2 or player 3. Your player number will remain the same throughout the experiment.

2. At the beginning of each round

a. You will be endowed with 250 ECUs that you can use to make the decisions within the round, as explained below.

b. You will be assigned a color (which will be immediately revealed to you) whose value for you is explained below.

3. At each round, you and the other players in your group will have the possibility to buy one object, by bidding in an auction (the auction rules will be detailed below). There will be one auctioned object, which can be either orange or green. The earnings of a player in case of obtaining the auctioned object depend on the color of the object:

- If the object is equal to the player's assigned color, then the player will earn 200 ECUs.

- If the object is different from the player's assigned color, then the player will earn 100 ECUs.

\footnotetext{
${ }^{22} \mathrm{We}$ omit the experiment instructions of the Uninterested and Base treatments, which are variations of the instructions of the Soft treatment (as explained in Sections 3 and 4). These instructions are available from the authors upon request.
} 
4. At the beginning of each round, the object to be auctioned is randomly drawn by the computer from one (virtual) urn containing two objects: one orange object and one green object. Each object is picked with equal probability (50\%).

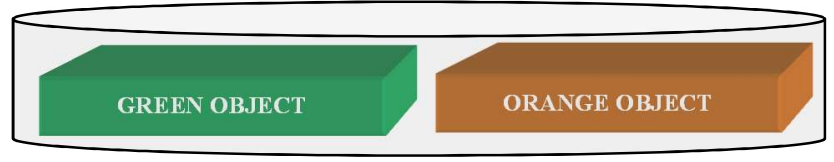

The colors assigned to players 1,2 and 3 for the round are determined in a similar way. There is one (virtual) urn for each of these three players containing two pieces of paper: one orange and one green. The computer randomly (and independently) draws one piece of paper from each urn. Each piece of paper is picked with equal probability (50\%). The piece of paper selected for each player determines that player's assigned color for the round.
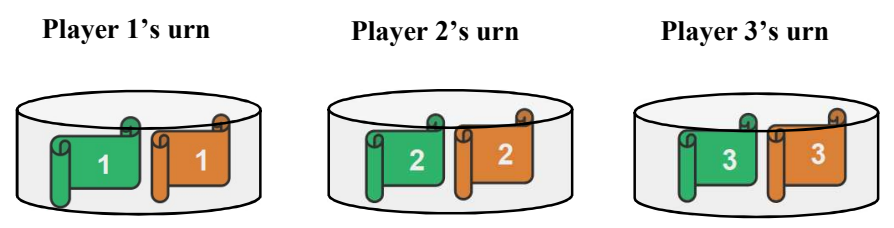

5. In each round, each player will make his decisions knowing his preferred color but not others' preferred colors.

FOR EXAMPLE,

if in a round the selected colors for players 1,2 and 3 are

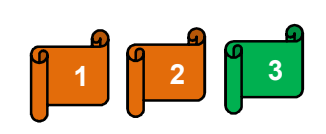

- Then, player 2 will know 19 about the colors of players 1 and 3 is that one of the next four combinations has been drawn, each of them with equal probability $(25 \%)$ :

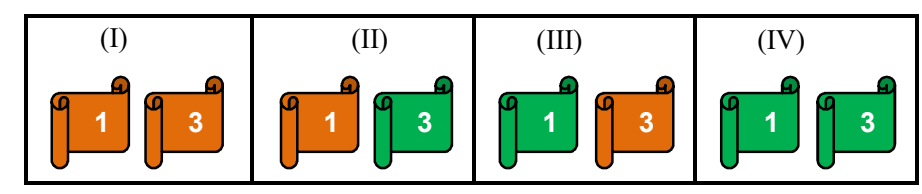

- An analogous line of reasoning holds for players 1 and 3 (they know only their own assigned colors).

6. Initially, no player will know which object (orange or green) has been selected by the computer for the round. However, prior to the auction, in sequence, you and the other players in the group will have the possibility to become informed of the color of the 
object to be auctioned by paying 20 ECUs. These decisions will be made according to the following sequence: first player 1, then player 2 (knowing player 1's choice), and finally player 3 (knowing player 1's and player 2's choices).

7. The color of the object will be revealed to all those players that have decided to become informed (see the previous point). Then, if at least one player has decided to acquire the information and at least one player has decided not to acquire it, there will be a market for reports. In such a case, prior to the auction, the players that have acquired the information will be able to sell a report about the color of the object to the uninformed players. In all other cases, all the players will directly participate in the auction.

These are the rules of the market for reports:

i. First, those players who have acquired the information and that now know the color of the object will choose whether to sell a report or not. In case they decide to sell a report, these players will set a price (for their report) and all the other players will observe this price.

ii. The price of the report cannot exceed 20 ECUs.

iii. According to the sequence (player 1 - player 2 - player 3), the uninformed players will decide whether to buy one of the reports. When a player makes his choice, he will learn the decisions of those players who acted before him/her in the sequence.

iv. The players who have sold a report will decide on the content of the report. The content can be as follows: "The object is orange", "The object is green" or "The object is orange or green". Thus, the report can contain the true color, contain the false one, or be uninformative.

v. The buyers of the report will receive it.

When the market for reports finishes, all the players will participate in the auction, making a bid for the object.

8. Auction rules: The player that makes the highest bid will obtain the object. However, this player will pay not his bid, but the second-highest bid. The other players will neither obtain the object nor pay anything. 
For example: If player 1 bids 8 ECUs, player 2 bids 55 ECUs, and player 3 bids 18 ECUs, then player 2 (the highest bidder) will receive the object and pay 18 ECUs for it (the second-highest bid). Players 0,1 and 3 will neither receive the object nor pay anything.

In case of ties in the highest bids, the computer will randomly pick (with equal probability) the player who receives the object from among those players who have made the highest bid. In such a case, the player who receives the object will pay his own bid, and the remaining players will neither receive the object nor pay anything.

For example: If player 1 bids 55 ECUs, player 2 bids 55 ECUs, and player 3 bids 18 ECUs, then either player 1 or player 2 will obtain the object, with equal probability. The player who receives the object will pay 55 ECUs.

9. Summary of round payoffs. The round payoff of a player will have three parts:

a. The player will receive the endowment (250 ECUs) minus the payments (if any) incurred either to be informed or to buy a report.

b. In the event of having sold reports, the player will obtain the agreed price from each buyer.

c. In the event of winning the auctioned object, the player will obtain either 200 ECUs (if the object is of his assigned color) or 100 ECUs (if it is not) minus his payment in the auction.

10. After the auction, and before proceeding to the next round, each player will receive the following ex post information:
a. The bids made by each player in the auction.
b. The player who obtained the auctioned object and the price paid for it.
c. The color of the auctioned object.

His round payoff (disaggregated).

11. Payments. At the end of the experiment, you will be paid your payoffs from 4 of the 20 rounds. These rounds will be randomly selected by the computer. The payoffs that you obtained in the selected 4 rounds will be converted into euros at the rate 100 ECUs $=1$ euro and will be paid to you in private.

\section{A.2 Experimental instructions for the Hard treatment}


The instructions of the Hard treatment differ from the instructions of the Soft treatment only on point 7 . In particular, item $i v$ (dealing with the decision on the content of the report) is removed. Instead, we add the sentence "The report reveals the true color of the object" as a new item just after the sentence "These are the rules of the market for reports". 


\section{B) UNINTERESTED TREATMENTS}

In this section, we describe the characteristics and the results of the Uninterested20 and Uninterested-10 treatments.

The informative equilibrium for the game we consider in these two treatments is as follows: ${ }^{23}$ player 0 acquires information and sells a report to two buyers at a price of 12.5 ECUs. The report sent is always truthful. Thus, two of the players participating in the auction learn the true color of the object, and the remaining bidder remains uninformed.

In Table B1, we report the bidding behavior of the different types of players (according to the information they hold) in the auction.

Table B1. Average bids by treatment, type of player and block of 10 rounds

\begin{tabular}{|c|c|c|c|c|c|}
\hline & & \multicolumn{2}{|c|}{ Uninterested-20 } & \multicolumn{2}{|c|}{ Uninterested-10 } \\
\hline & & $\begin{array}{l}\text { Rounds } \\
1-10\end{array}$ & $\begin{array}{c}\text { Rounds } \\
11-20\end{array}$ & $\begin{array}{c}\text { Rounds } \\
1-10\end{array}$ & $\begin{array}{c}\text { Rounds } \\
11-20\end{array}$ \\
\hline \multirow{2}{*}{$\begin{array}{l}\text { Informed } \\
\text { players }\end{array}$} & Color-Yes [Prediction: 200] & $144.46^{\wedge}$ & 191.51 & $160.73^{*}$ & 195.84 \\
\hline & Color - No [Prediction: 100] & 68.13 & 90.98 & 78.21 & 115.33 \\
\hline $\begin{array}{l}\text { Uninformed } \\
\text { players }\end{array}$ & [Prediction: 150] & 120.15 & 141.85 & 130.14 & 140.54 \\
\hline \multirow{3}{*}{$\begin{array}{l}\text { Buyers of } \\
\text { report }\end{array}$} & $\begin{array}{l}\text { Content: Color - Yes } \\
\text { [Prediction: 200] }\end{array}$ & 131.84 & 161.60 & 153.76 & 177.55 \\
\hline & $\begin{array}{l}\text { Content: Color - No } \\
\text { [Prediction: 100] }\end{array}$ & 80.48 & 84.27 & 100.43 & 94.83 \\
\hline & $\begin{array}{l}\text { Content: } 0 \\
\text { [Prediction: 150] }\end{array}$ & 47.33 & 81.00 & 30.00 & 153.29 \\
\hline
\end{tabular}

Mann-Whitney test significance at ${ }^{* * *} p<0.01,{ }^{* *} p<0.05,{ }^{*} p<0.1$

t-test significance at $\wedge^{\wedge \wedge} p<0.01, \wedge \wedge p<0.05, \wedge p<0.1$

As shown by the reported results of the Mann-Whitney test and t-test, we find that there are no systematic significant differences in the bids between treatments by periods and type of available information that the subjects have. Moreover, we observe a learning pattern common to both treatments (and all types of available information): in the second half of the experiment, the bids increase and approach the values from the theoretical predictions.

\footnotetext{
${ }^{23}$ See $C G$ for a proof.
} 
In Table B2, we describe the observed behavior in the information market. We report the choices made by (interested) players regarding the acquisition of information by blocks of 10 rounds.

Table B2. Behavior in information markets in the Uninterested-20 and Uninterested10 treatments of interested players - absolute number of observations and relative frequencies $(\%$ over row total)

\begin{tabular}{|l|l|l|l|l|l|l|}
\hline & \multicolumn{3}{|c|}{ Rounds 1-10 } & \multicolumn{3}{c|}{ Rounds 11-20 } \\
\cline { 2 - 7 } & Uninformed & Informed & Buy a report & Uninformed & Informed & Buy a report \\
\hline \multirow{3}{*}{ Uninterested-20 } & $\begin{array}{l}168 \\
(46.67)\end{array}$ & $\begin{array}{l}136 \\
(37.78)\end{array}$ & $\begin{array}{l}56 \\
(15.56)\end{array}$ & $\begin{array}{l}228^{\wedge \wedge \wedge} \\
(63.33)\end{array}$ & $\begin{array}{l}97^{\wedge \wedge} \\
(26.94)\end{array}$ & $\begin{array}{l}35^{\wedge} \\
(9.72)\end{array}$ \\
\hline \multirow{3}{*}{ Uninterested-10 } & $\begin{array}{l}134 \\
(45.76)\end{array}$ & $\begin{array}{l}121 \\
(38.94)\end{array}$ & $\begin{array}{l}45 \\
(15.00)\end{array}$ & $\begin{array}{l}168^{\wedge \wedge} \\
(56.00)\end{array}$ & $\begin{array}{l}73^{\wedge \wedge \wedge} \\
(24.33)\end{array}$ & $\begin{array}{l}59^{* *} \\
(14.24)\end{array}$ \\
\hline
\end{tabular}

Unint-20 vs. Unint-10: Mann-Whitney test significance at ${ }^{* * *} p<0.01,{ }^{* *} p<0.05,{ }^{*} p<0.1$ Periods 1-10 vs. 11-20: Signed-rank test significance at $\wedge \wedge \wedge p<0.01, \wedge \wedge p<0.05, \wedge p<0.1$

In both treatments, we find that the frequencies of buying a report are much lower than the values of the theoretical predictions (66\%). These frequencies are very similar across treatments in the first 10 rounds (approximately 15\%). In the second half of the experiment, the frequency of reports bought falls by one-third in treatment Uninterested20, whereas it remains stable in treatment Uninterested-10, with the difference between both treatments being statistically significant (Mann-Whitney test). Moreover, in both treatments, we observe that the modal choice is to remain uninformed and that the frequency of this choice increases in the last 10 rounds.

In Table B3, we report the behavior of the uninterested player (player 0) regarding information acquisition by block of 10 rounds.

Table B3. Behavior in the information market of player 0 in the Uninterested-20 and Uninterested-10 treatments - absolute number of observations and relative frequencies (\% over row total)

\begin{tabular}{|l|c|c|c|c|}
\hline & \multicolumn{2}{|c|}{ Rounds 1-10 } & \multicolumn{2}{c|}{ Rounds 11-20 } \\
\hline & Not informed & Informed & Not informed & Informed \\
\hline Uninterested-20 & $\begin{array}{c}46 \\
(38.33)\end{array}$ & $\begin{array}{c}74 \\
(61.67)\end{array}$ & $\begin{array}{c}71^{\wedge} \\
(59.17)\end{array}$ & $\begin{array}{c}49^{\wedge} \\
(40.83)\end{array}$ \\
\hline Uninterested-10 & $\begin{array}{c}14^{* *} \\
(14.00)\end{array}$ & $\begin{array}{c}86^{* *} \\
(86.00)\end{array}$ & $\begin{array}{c}19^{* *} \\
(19.00)\end{array}$ & $\begin{array}{c}81^{* *} \\
(81.00)\end{array}$ \\
\hline
\end{tabular}

Unint-20 vs. Unint-10: Mann-Whitney test significance at $* * * p<0.01,{ }^{* *} p<0.05, * p<0.1$

Periods 1-10 vs. 11-20: Signed-rank test significance at $\wedge^{\wedge \wedge} p<0.01, \wedge \wedge p<0.05, \wedge p<0.1$ 
Here, on the supply side of reports, we observe remarkable differences between the treatments. In Uninterested-10, a high majority of uninterested players choose to acquire the information in the first 10 rounds, and this frequency remains stable in the latter half of the experiment (above 80\%). In the Uninterested-20 treatment, the modal choice in the first 10 rounds is still to acquire information, although this frequency (approximately 60\%) is significantly lower than that in the Uninterested-10 treatment. Moreover, this frequency significantly decreases in the second half of the experiment, and the modal choice for player 0 becomes to remain uninformed.

In Table B4, we describe the informational content of the reports sent for each treatment.

Table B4. Content of the sent report by treatment - absolute number of observations and relative frequencies (\% over row total)

\begin{tabular}{|c|ccc|c|}
\hline \multicolumn{1}{|c}{ Seller } & O report & False report & \multicolumn{1}{c|}{ Truthful report } & Total \\
\hline Uninterested-20 & 7 & 4 & 58 & 69 \\
& $(10.14)$ & $(5.80)$ & $(84.06)$ & $(100)$ \\
Uninterested-10 & 6 & 1 & 79 & 86 \\
& $(6.98)$ & $(1.16)$ & $(91.86)$ & $(100)$ \\
\hline
\end{tabular}

Unint-20 vs. Unint-10: Mann-Whitney test significance at ${ }^{* * *} p<0.01,{ }^{* *} p<0.05,{ }^{*} p<0.1$

We observe that in both treatments, a large majority of the reports are truthful, with this frequency being slightly higher in Uninterested-10 (with the difference not being statistically significant).

In Table B5, we present the (average) asking prices by the sellers of reports in the two treatments by blocks of 10 rounds.

Table B5. Asking price in the market for reports

\begin{tabular}{|l|l|l|}
\hline & \multicolumn{1}{|c|}{ Rounds 1-10 } & \multicolumn{1}{c|}{ Rounds 11-20 } \\
\hline Unint-20 & $13.79 \quad$ & 13.54 \\
\hline Unint-10 & 12.62 & 12.39 \\
\hline
\end{tabular}

Unint-20 vs. Unint-10: Mann-Whitney test significance at $* * * p<0.01,{ }^{* *} p<0.05, * p<0.1$

Rounds 1-10 vs. $11-20$ : Signed-Rank test significance at ${ }^{\wedge \wedge} p<<0.01, \wedge \wedge p<0.05, \wedge p<0.1$

We observe that prices are very similar across treatments and stable over time. These prices are very close to the theoretical prediction (12.5).

In Table B6, we describe the (average) accepted prices and acceptance rates in the two treatments by blocks of 10 rounds. 
Table B6. Accepted price and Acceptance rate in the market for reports

\begin{tabular}{|l|l|l|l|}
\hline & & Rounds 1-10 & Rounds 11-20 \\
\hline \multirow{2}{*}{ Accepted Price } & Unint-20 & 12.84 & 12.23 \\
\cline { 2 - 4 } & Unint-10 & 10.44 & 11.98 \\
\hline \multirow{2}{*}{ Acceptance Rate } & Unint-20 & 0.203 & $0.184^{\wedge}$ \\
\cline { 2 - 4 } & Unint-10 & 0.139 & 0.185 \\
\hline
\end{tabular}

Unint-20 vs. Unint-10: Mann-Whitney test significance at *** $p<0.01,{ }^{* *} p<0.05, * p<0.1$

Rounds 1-10 vs. 11-20: Signed-Rank test significance at ${ }^{\wedge \wedge \wedge} p<0.01, \wedge \wedge p<0.05, \wedge p<0.1$

The accepted price is also quite close to the theoretical prediction in both treatments (it is just slightly below the average asking price), with no significant differences across treatments or blocks of rounds. Regarding the acceptance rate (that is, the frequency of cases in which the seller of information - player 0 - sells at least two reports, conditional on buying the information), it is between $14 \%$ and $20 \%$, which is far below the theoretical prediction (100\%). There are no significant differences between treatments or blocks of rounds (with the exception of the comparison across blocks of rounds in the Unint-20 treatment, which is marginally significant).

In Table B7, we present the distribution of the number of reports sold (conditional on player 0 having acquired information).

Table B7. Distribution of the number of sold reports

\begin{tabular}{|l|l|l|l|l|}
\hline & 0 & 1 & 2 & 3 \\
\hline Uninterested-20 & $49(41.53)$ & $50(42.37)$ & $16(13.56)$ & $3(2.54)$ \\
\hline Uninterested-10 & $71(45.51)$ & $69(44.23)$ & $14(8.97)$ & $2(1.28)$ \\
\hline
\end{tabular}

Pearson chi2 $(3)=2.1720 \operatorname{Pr}=0.537$

We observe that the density is concentrated on selling either 0 reports or 1 report, with roughly the same probability in each treatment. Thus, we observe significant deviations from the theoretical prediction, in which 2 reports are sold.

In Table B8, we present the average earnings of subjects, depending on the treatment, information condition and block of 10 rounds. The most relevant difference that we observe in earnings across the two treatments concerns the uninterested players who choose to acquire information: their payoff is higher in the Uninterested-10 treatment compared to the Uninterested-20 treatment. 
Table B8. Average earnings by treatment, type of available information and rounds

\begin{tabular}{|l|l|l|}
\hline & \multicolumn{2}{|c|}{ Uninterested-20 } \\
\hline & Rounds 1-10 & Rounds 11-20 \\
\hline Uninterested (when informed) & 239.72 & 238.73 \\
\hline Uninformed & 268.74 & 256.35 \\
\hline Informed & 247.17 & $244.34^{\wedge}$ \\
\hline Buyers of reports & 257.71 & 251.07 \\
\hline & \multicolumn{2}{|c|}{ Uninterested-10 } \\
\hline & Rounds 1-10 & Rounds 11-20 \\
\hline Uninterested (when informed) & $245.47^{* * *}$ & $248.73^{* * *}$ \\
\hline Uninformed & 253.78 & 251.19 \\
\hline Informed & 252.59 & $233.30^{\wedge}$ \\
\hline Buyers of reports & 258.62 & $242.56^{\wedge}$ \\
\hline
\end{tabular}

Unint-20 vs. Unint-10: Mann-Whitney test significance at *** $p<0.01,{ }^{* *} p<0.05,{ }^{*} p<0.1$

Rounds 1-10 vs. 11-20: Signed-rank test significance at $\wedge^{\wedge \wedge} p<0.01, \wedge \wedge p<0.05, \wedge p<0.1$ 


\section{C) BASE TREATMENT}

Here, we present the main experimental results for the Base treatment regarding the market for reports. In Table C1, analogous to Table 3 in the main text, we present the frequencies of the participants' choices in the experiment to (i) acquire information in the first stage (Inform), (ii) buy a report in the second stage (Buy rep) and (iii) remain uninformed (Uninf), distinguishing by mover and by block of 10 rounds.

Table C1. Behavior in information markets - absolute number of observations and relative frequencies (\% over row total)

\begin{tabular}{lcccccc}
\hline & \multicolumn{3}{c}{ Rounds 1-10 } & \multicolumn{3}{c}{ Rounds 11-20 } \\
& Uninf. & Inform. & Buy rep. & Uninf. & Inform. & Buy rep. \\
\hline \multirow{2}{*}{ Total } & 208 & $\mathbf{2 1 8}$ & 54 & $\mathbf{2 5 5}$ & 192 & 33 \\
& $(43.33)$ & $\mathbf{( 4 5 . 4 2 )}$ & $(11.25)$ & $\mathbf{( 5 3 . 1 3 )}$ & $(40.00)$ & $(6.88)$ \\
\hline
\end{tabular}

The distribution of available information is very similar to that in the Soft treatment, with the same modal choices. In particular, we highlight that the frequency with which reports are purchased is also reduced in the second half of the experiment, where we find that the market for reports progressively collapses (the average frequency is $6.88 \%$, with almost no activity in the last rounds). These results show that as in the Soft treatment, the market for reports is never very large and ultimately collapses.

In Table C2, analogous to Table 4, we present the content of the reports, distinguishing between the case in which the seller is interested in the object and the case in which he is not interested.

Table C2. Content of the report by type of seller (interested in the object or uninterested) - absolute number of observations and relative frequencies ( $\%$ over row total)

\begin{tabular}{|c|ccc|c|}
\hline \multicolumn{1}{|c}{ Seller } & O report & False report & \multicolumn{1}{c|}{ Truthful report } & Total \\
\hline \multirow{2}{*}{ Uninterested } & 10 & 10 & $\mathbf{2 8}$ & 48 \\
& $(20.83)$ & $(20.83)$ & $\mathbf{( 5 8 . 3 3 )}$ & $(100)$ \\
Interested & 12 & 7 & $\mathbf{1 4}$ & 33 \\
& $(36.36)$ & $(21.21)$ & $\mathbf{( 4 0 . 4 2 )}$ & $(100)$ \\
Total & 22 & 17 & $\mathbf{4 2}$ & 81 \\
& $(27.16)$ & $(20.99)$ & $\mathbf{( 5 1 . 8 5 )}$ & $(100)$ \\
\hline
\end{tabular}

As in the Soft treatment, we observe a high frequency of empty and false reports even in situations where a true report is expected. 
In Table $\mathrm{C} 3$, we report the averages of the minimum asking price and accepted price observed in the market for reports. Again, these values are consistent with those observed in the Soft treatment (see Tables 6 and 7).

Table C3. Minimum asking price and accepted price in the market for reports

\begin{tabular}{lcc}
\hline & Periods 1-10 & Periods 11-20 \\
\hline Minimum asking price & 8.83 & 6.97 \\
Accepted price & 7.78 & 6.24 \\
\hline
\end{tabular}




\section{D) REGRESSION ANALYSIS OF SUBJECTS' BEHAVIOR IN THE INFORMATION MARKET}

To provide some further explanations for our findings regarding the different performance of the market for reports with hard and soft information, we investigate in more detail the determinants of the key decisions in this market: (i) whether to buy a report, (ii) whether to post a price for a report and (iii) what content to include in the message in the Soft treatment (that is, the quality of the information transmitted). On the latter, we should point out that the quite limited size of the market for information in treatment Soft prevents a proper statistical analysis of that decision (the total number of reports sold is only 71, and only 26 in the second half of the experiment, considerably lower than the number of times the game was played (340, as there were 20 iterations per group and a total of 17 groups), and much lower than the number predicted by the equilibrium considered where a report is sold every time the game is played). In what follows, we will thus focus on the first two decisions.

(i) Regarding the decision to buy reports, notice that to be able to participate as a buyer in the market for reports, a subject must have chosen not to acquire information directly in the first stage. For this reason, we jointly estimate the Selection equation (the probability of not acquiring information in the first stage) and the Buying a report equation (the probability of buying a report in the second stage, given that the player did not acquire information directly).

(ii) Regarding the decision to post a price, note that to be able to participate as a seller in the market for reports, a subject must have chosen to acquire information directly in the first stage. Thus, we jointly estimate the Selection equation (the probability of acquiring information in the first stage) and the Posting a price equation (the probability of posting a price in the second stage, given that the player did acquire information directly).

Our models (i)-(ii) are quite similar to a Heckman probit estimation (which allows for the possibility of correlation between the selection and the report equations, measured by parameter Rho in Table D1). In addition, we need to account for the fact that to be able to participate in the market for reports, another condition is required. In model (i), at least one player in the group must have acquired the information in the first stage and posted a price (i.e., there has to be a seller), and in model (ii), at least one player in the group must 
not have acquired the information in the first stage (i.e., there has to be a buyer). ${ }^{24} \mathrm{We}$ cluster standard errors at the group level to account for the correlation arising from the fact that a group interacts for 20 periods. ${ }^{25}$

Therefore, we estimate 4 models, and the results are reported in Table D1. In models (1) and (2), we estimate for the Soft treatment the determinants of the decision to buy a report and the determinants of the decision to post a price, respectively. In models (3) and (4), we carry out the same analysis for the Hard treatment. In the upper (lower) panel of Table D1, we report the estimation results for the corresponding Selection equation (respectively, Buying a report, Posting a price). The variables included in the Selection equations are:

- round, a variable that represents the number of iterations of the game (from 1 to 20);

- info_1, a dummy variable that takes value 1 if the subject acts as mover 2 and the predecessor (mover 1) has directly acquired the information and value 0 otherwise;

- info_12, a variable that takes value 1 if the subject is mover 3 and at least one predecessor has directly acquired the information and value 0 otherwise;

- $\quad e n v \mid n p$, a variable that takes value $1(0)$ if the subject is (is not) classified either as envious or nonprosocial according to his choices in the dictator games described in Table E1;

- risk, a variable that measures how risk loving that player is (represents the amount from 0 to 5 - invested by the subject in the risky asset in the risk test);

- mover 2, a dummy variable that takes value $1(0)$ if the subject acts (does not act) as mover 2;

- mover3, a dummy variable that takes value $1(0)$ if the subject acts (does not act) as mover 3;

- true_cum, a cumulative variable that reports the difference between the number of previous rounds in which the subject bought a report containing a true message and the number of previous rounds in which he bought a report containing a false or uninformative message (it takes value 0 if the subject has not bought any reports yet); and

\footnotetext{
${ }^{24}$ For this reason, we could not use the standard Stata command for Heckman probit estimation, and needed to program it ourselves. The program is available upon request.

${ }^{25}$ The Stata program to perform these estimations is available from the authors upon request.
} 
- L_acquire_inf, a (lagged) variable that takes value 1 if the subject acquired information directly in the previous round, and value 0 otherwise.

Note that true_cum is intended to capture the effects of previous experience with purchasing reports on subsequent information acquisitions. For this reason, it is included only in the estimations for the decision to buy a report in the Soft treatment (in the Hard treatment, by design, all reports are truthful).

The variables included in the Buying a report equations are round, env $\mid n p$, risk, true_cum and

- inf_tot, a variable that measures the number of subjects in the group that directly acquired the information (i.e., the number of potential sellers of reports); and

- askmin, a variable that measures the lowest price posted in the group.

The variables included in the Posting a price equations are round, inf_tot, env $\mid n p$, risk and

- noint, a dummy variable that takes value 1 if the subject is not interested in the object and 0 otherwise,

as well as the interactions of this last variable with the antisocial preference variable $\left(\right.$ noint $\left.{ }^{*} e n v \mid n p\right)$ and with the risk variable (noint ${ }^{*}$ risk).

The selection equation of model (1) of Table D1 shows that the probability of not acquiring the information directly in the Soft treatment (and therefore of being selected to participate as buyers in the market for reports) is increasing in round (significant at 1\%). Moreover, it shows that the fact that a player acquired the information directly in the previous round increases the likelihood that he does the same in the current round (and therefore is not selected to act as buyer in the market for reports), as shown by the negative and significant coefficient of $L$ _acquire_inf. This confirms what we mentioned earlier. The participants in the experiment realize that information quality in the market for reports is too low given its price and simply drop out of the market.

Regarding the Buying a report equation, the main determinants of buying a report turn out to be the variables true_cum and askmin. The fact that true_cum is positive and significant suggests that previous experiences in the market for reports are important to making this decision: subjects who have accumulated bad experiences in the past are less likely to buy a report. We also note that the fact that askmin is negative and significant shows that higher prices result in less activity in the market for reports (as argued earlier, 
the prices posted in the Soft treatment turn out to be higher, on average, than the value of the information contained in them). Finally, the coefficient of round is negative and significant (at the 10\% level), showing the decline across rounds of purchases of reports in the Soft treatment. Additionally, inf_tot is (marginally) significant, suggesting that having two rather than one potential seller of information may increase the probability of buying reports.

Table D1. Market for reports: decision to post a price and decision to buy a report

\begin{tabular}{|c|c|c|c|c|}
\hline & \multicolumn{2}{|c|}{ Soft Treatment } & \multicolumn{2}{|c|}{ Hard Treatment } \\
\hline & $\begin{array}{c}\text { Buying a report } \\
\text { (1) }\end{array}$ & $\begin{array}{c}\text { Posting a price } \\
\text { (2) }\end{array}$ & $\begin{array}{c}\text { Buying a report } \\
\text { (3) }\end{array}$ & $\begin{array}{c}\text { Posting a price } \\
\text { (4) }\end{array}$ \\
\hline & \multicolumn{4}{|c|}{ Selection equation } \\
\hline Cons & $\begin{array}{c}0.1028 \\
(0.2397) \\
\end{array}$ & $\begin{array}{l}-0.1136 \\
(0.2370)\end{array}$ & $\begin{array}{c}0.7948 * \\
(0.4686) \\
\end{array}$ & $\begin{array}{l}-0.7977^{* *} \\
(0.3258)\end{array}$ \\
\hline Round & $\begin{array}{l}0.0399 * * * \\
(0.0116)\end{array}$ & $\begin{array}{l}-0.0399 * * * \\
(0.0117)\end{array}$ & $\begin{array}{l}0.0183^{* * *} \\
(0.0070)\end{array}$ & $\begin{array}{l}-0.0180^{* * *} \\
(0.0068)\end{array}$ \\
\hline info1 & $\begin{array}{c}0.1868 \\
(0.2229) \\
\end{array}$ & $\begin{array}{l}-0.2483 \\
(0.2332) \\
\end{array}$ & $\begin{array}{c}0.5047 \\
(0.4987) \\
\end{array}$ & $\begin{array}{l}-0.4734 * * \\
(0.1992)\end{array}$ \\
\hline info12 & \begin{tabular}{|l|}
-0.2457 \\
$(0.2796)$
\end{tabular} & $\begin{array}{c}0.2339 \\
(0.2896)\end{array}$ & $\begin{array}{l}0.9206^{* * *} \\
(0.2850)\end{array}$ & $\begin{array}{l}-0.9054 * * * \\
(0.2413)\end{array}$ \\
\hline$e n v / n p$ & $\begin{array}{l}-0.0829 \\
(0.1476)\end{array}$ & $\begin{array}{c}0.0923 \\
(0.1337) \\
\end{array}$ & $\begin{array}{l}-0.1004 \\
(0.1413)\end{array}$ & $\begin{array}{c}0.1000 \\
(0.1378) \\
\end{array}$ \\
\hline risk & \begin{tabular}{|l|}
-0.0377 \\
$(0.0406)$
\end{tabular} & $\begin{array}{c}0.0378 \\
(0.0404) \\
\end{array}$ & $\begin{array}{l}-0.1821^{* *} \\
(0.0773)\end{array}$ & $\begin{array}{l}0.1803^{* *} \\
(0.0733)\end{array}$ \\
\hline mover2 & \begin{tabular}{|l|}
-0.2907 \\
$(0.1890)$
\end{tabular} & $\begin{array}{c}0.3383^{*} \\
(0.1870)\end{array}$ & $\begin{array}{l}-0.3657^{*} \\
(0.2057)\end{array}$ & $\begin{array}{c}0.3451 * \\
(0.1849)\end{array}$ \\
\hline mover3 & $\begin{array}{l}-0.0518 \\
(0.2678) \\
\end{array}$ & $\begin{array}{c}0.0668 \\
(0.2924) \\
\end{array}$ & $\begin{array}{l}-0.8249 * * \\
(0.3465)\end{array}$ & $\begin{array}{l}0.8169 * * * \\
(0.2670)\end{array}$ \\
\hline true_cum & \begin{tabular}{|c|}
0.0073 \\
$(0.0731)$
\end{tabular} & & & \\
\hline L_acquire_inf & $\begin{array}{l}-0.6075^{* * *} \\
(0.1727)\end{array}$ & $\begin{array}{l}0.5991^{* * *} \\
(.1740)\end{array}$ & $\begin{array}{l}-0.5952^{* * *} \\
(0.1634)\end{array}$ & $\begin{array}{l}0.6077^{* * *} \\
(0.1175)\end{array}$ \\
\hline \multirow[t]{2}{*}{ N. Obs. } & 969 & 969 & 912 & 912 \\
\hline & \multicolumn{4}{|c|}{ Buying a report/Posting a price equation } \\
\hline Cons & $\begin{array}{l}-1.1201 * * * \\
(0.4187)\end{array}$ & $\begin{array}{r}1.5592 \\
(.9677)\end{array}$ & $\begin{array}{c}0.6963 \\
(1.0740)\end{array}$ & $\begin{array}{l}-0.8929 * * \\
(0.3513)\end{array}$ \\
\hline Round & $\begin{array}{l}-0.0443^{*} \\
(0.0240)\end{array}$ & $\begin{array}{l}-0.0815^{* * *} \\
(0.0272)\end{array}$ & $\begin{array}{l}-0.0204 \\
(0.0260)\end{array}$ & $\begin{array}{l}-0.0039 \\
(0.0117) \\
\end{array}$ \\
\hline inf_tot & $\begin{array}{c}0.2596 * \\
(0.1527) \\
\end{array}$ & $\begin{array}{l}-0.1670 \\
(.2438) \\
\end{array}$ & $\begin{array}{l}0.6469 * * \\
(0.3039)\end{array}$ & $\begin{array}{c}0.2137 \\
(0.2673) \\
\end{array}$ \\
\hline env/np & $\begin{array}{c}0.5528 \\
(0.3968)\end{array}$ & $\begin{array}{c}0.0634 \\
(0.4436)\end{array}$ & $\begin{array}{l}-0.6505^{* *} \\
(0.3142)\end{array}$ & $\begin{array}{l}0.5802 * * * \\
(0.2102)\end{array}$ \\
\hline Risk & \begin{tabular}{|c|}
0.0106 \\
$(0.0492)$ \\
\end{tabular} & $\begin{array}{c}0.1712 \\
(0.1246) \\
\end{array}$ & \begin{tabular}{|l|l}
-0.0164 \\
$(0.2439)$ \\
\end{tabular} & \begin{tabular}{|l}
$0.1391^{* *}$ \\
$(0.0603)$ \\
\end{tabular} \\
\hline Askmin & $\begin{array}{l}-0.0702^{* * *} \\
(0.0269)\end{array}$ & & $\begin{array}{l}-0.0632 * * * \\
(0.0245)\end{array}$ & \\
\hline true_cum & $\begin{array}{c}0.2250^{* *} \\
(0.1029)\end{array}$ & & & \\
\hline
\end{tabular}




\begin{tabular}{|l|l|l|l|l|}
\hline Noint & & $\begin{array}{l}-0.1883 \\
(0.4737)\end{array}$ & & $\begin{array}{l}1.4870^{* * *} \\
(0.4612)\end{array}$ \\
\hline noint ${ }^{*}$ env/np & & $\begin{array}{l}0.4786 \\
(0.4285)\end{array}$ & & $-0.6594^{* *}$ \\
& & -0.0216 & & $-3299)$ \\
\hline \multirow{2}{*}{ noint*risk } & & $(0.0900)$ & & -0.2086 \\
& & 363 & 403 & 396 \\
\hline N. Obs. & 447 & 0.1859 & -0.0918 & $(1.7796)$ \\
\hline Rho & $0.8241^{* * *}$ & $(0.7809)$ & $(0.4410)$ \\
\hline
\end{tabular}

$* * *, * *$, and $*$ indicate significance at the $1 \%, 5 \%$, and $10 \%$ levels, respectively.

If we turn our attention to the decision to post a price in the Soft treatment (model (2)), we observe that the Selection equation is almost the 'inverse mirror image' of the one reported in model (1), reflecting the fact that, basically, those variables that increase the probability of being selected to participate as buyers in the market for reports decrease the probability of being selected to participate as sellers. In the Posting a price equation, only the variable round is significant, showing that the number of subjects who post a price decreases over time in the Soft treatment. One may argue these subjects feel discouraged by the observed decrease in acceptance rates in the market for reports (see Table 7). No other variable is significant, potentially because in the Soft treatment, the decision of whether to post a price is not crucial since the seller always has the possibility to undo the information transmission by sending an uninformative (or even false) message.

Next, we study the behavior in the Hard treatment, starting with the decision to buy a report. The results for model (3) of Table D1 show that the probability of not acquiring the information directly is increasing in round and decreasing in L_acquire_inf, as in the Soft treatment. However, now the variables info_l and info_ 12 are positive, with the latter being significant. At first sight, this suggests that the fact that other subjects moving earlier directly acquired information reduces the probability that later players acquire information. This would be quite reasonable in the Hard treatment, since players may be able to purchase truthful information in the market for reports in the later stages, potentially at a lower price. The variables mover 2 and mover 3 are negative and significant, suggesting that players that act later in the sequence are more likely to acquire direct information (therefore being less likely to act as buyers in the market for reports). Note, however, that the net effect of the coefficients of info_ 12 and mover 3 is very close to zero, meaning that the probability of mover 3 remaining uninformed is not significantly different from that of mover 1 when info_12 equals 1 . Conversely, when info_12 equals 
0 , this probability is significantly smaller. Finally, in this case, the variable risk is negative and significant, indicating that the more risk lover a player is, the higher the probability of acquiring direct information (note that this decision entails the risk of not being able to sell reports in subsequent stages).

Regarding the Buying a report equation of model (3), the variable inf_tot is positive and significant, showing that the presence of more sellers of information induces more reports to be bought. Though the result is similar to that for the Soft treatment, we should point out a difference from the Hard treatment that may be relevant here: having two sellers of information - despite this being an out-of-equilibrium event - may now mean that neither of them is interested in the object, making the information very valuable. Furthermore, $e n v \mid n p$ is now negative and significant, suggesting that subjects with antisocial traits are less likely to buy reports in the Hard treatment. As in treatment Soft, ask_min is negative and significant, implying that higher prices reduce purchases of reports.

Finally, we move to the analysis of the decision to post prices in the Hard treatment, corresponding to model (4). As in the previous treatment, we observe that the Selection equation is almost the 'inverse mirror image' of that reported in model (3). Regarding the Posting a price equation, recall that the behavior of subjects in this decision is one of the most puzzling features observed in the experiment, in light of the theory based on the standard preferences we postulated: namely, more than half of the interested players sell (hard) information, though this will lead to a significant decline in their own payoff in the auction. We see first that the coefficient of the variable noint is positive and significant, so that individuals not interested in the object are more likely to post a price. It is then particularly of interest to remark that both $e n v \mid n p$ and the interaction of this variable with noint are significant. Adding these two coefficients, we find that env|np has a significant effect only if the subject is interested. Thus, having antisocial traits increases the likelihood of posting a price when the seller of information is interested in the object. Social preferences therefore appear to play a role in explaining the puzzling behavior recalled above. An immediate explanation of the mechanism by which social preferences may operate is not apparent, and more work is needed to understand it. Here, we can just point out that by selling a report, the maximum achievable material gain over the other players increases, and subjects with antisocial traits may be attracted by this choice. 
Note that the coefficient of risk is positive and significant, though - again looking at the opposite sign of the interaction term of this variable with noint - only when the seller of information is interested in the object. Hence, risk aversion also affects the decision of interested subjects to post a price, in the sense that more risk-averse subjects post a price less frequently. A possible explanation is that by selling a report, an interested subject faces a "riskier lottery" in the auction stage, and hence, the more risk averse the agent is, the less willing he is to post a price.

Overall, the conclusion is that prosocial preferences appear to be a driver of the observed departures from equilibrium behavior in terms of price posting in the Hard treatment, while the experience of information being too noisy in the reports received in the Soft treatment contribute to driving buyers out of the market in that treatment. 


\section{E) RISK AND SOCIAL PREFERENCES TESTS}

In the risk test (Charness and Gneezy, 2010), subjects decide how much of their endowment ( 5 euros) to invest in a risky asset and how much to keep. They earn 2.5 times the amount invested if the asset is successful (prob. 0.5) and lose the amount invested otherwise.

In Table E1, we report the (dictator) games used for the elicitation of social preferences. Each subject had to make four decisions (one of them, randomly chosen, was paid). Each decision consists of a choice between distribution 1 and distribution 2. The choice of a distribution determines a payoff for the player and a payoff for another player.

Table E1. Games for the elicitation of social preferences

\begin{tabular}{lcc}
\hline $\begin{array}{c}\text { Game } \\
\text { (All payoffs in euros) }\end{array}$ & $\begin{array}{c}\text { Distribution } 1 \\
\text { self: } \text { other }\end{array}$ & $\begin{array}{c}\text { Distribution } 2 \\
\text { self: other }\end{array}$ \\
\hline (I) Prosociality & $2: 2$ & $2: 1$ \\
(II) Costly prosociality & $2: 2$ & $3: 1$ \\
\hline (III) Envy & $2: 2$ & $2: 4$ \\
(IV) Costly envy & $2: 2$ & $3: 5$ \\
\hline
\end{tabular}

According to the choices in these games, we can classify the subjects according to their prosociality and envy attitudes. Regarding prosociality (games I and II), those subjects choosing distribution 1 in game I and distribution 2 in game II are classified as weakly prosocial, and those choosing distribution 1 in both games are classified as strongly prosocial. In contrast, those choosing distribution 2 in both games are classified as nonprosocial. Regarding envy (games III and IV), the subjects choosing distribution 1 in game III and distribution 2 in game IV are classified as weakly envious, while those choosing distribution 1 in both games are classified as strongly envious. Those choosing distribution 2 in both games are classified as nonenvious. 


\section{F) SUPPLEMENTARY MATERIAL ON THE SOFT AND HARD}

\section{TREATMENTS}

In Table F1, we report the average gross payoff in the auction, computed as the average of the value of the object minus the price paid for it if the player obtains the object and 0 otherwise. Informed players, as predicted, are those that earn more in the auction. Moreover, we note a reduction of the auction's earnings across blocks of periods. This reduction is due to the combination of increasing bids (across blocks of periods) and the preference of the players to acquire information directly.

Table F1. Average (gross) payoffs in the auction by treatment, type of available information and block of rounds

\begin{tabular}{|l|l|l|}
\hline & \multicolumn{2}{|c|}{ Soft treatment } \\
\hline & Rounds 1-10 & Rounds 11-20 \\
\hline Uninformed & 6.60 & 1.63 \\
\hline Informed & 15.62 & 9.69 \\
\hline Buyers of reports & 4.24 & 5.50 \\
\hline & \multicolumn{2}{|c|}{ Hard treatment } \\
\hline & Rounds 1-10 & Rounds 11-20 \\
\hline Uninformed & 9.23 & -3.31 \\
\hline Informed & 24.88 & 5.46 \\
\hline Buyers of reports & 13.80 & 3.93 \\
\hline
\end{tabular}

In Figure F1, we depict the histogram for the informational content of reports (frequency of true messages) across groups in the Soft treatment. It suggests that there is some group variation.

Figure F1. Frequency of truthful messages across groups in the Soft treatment

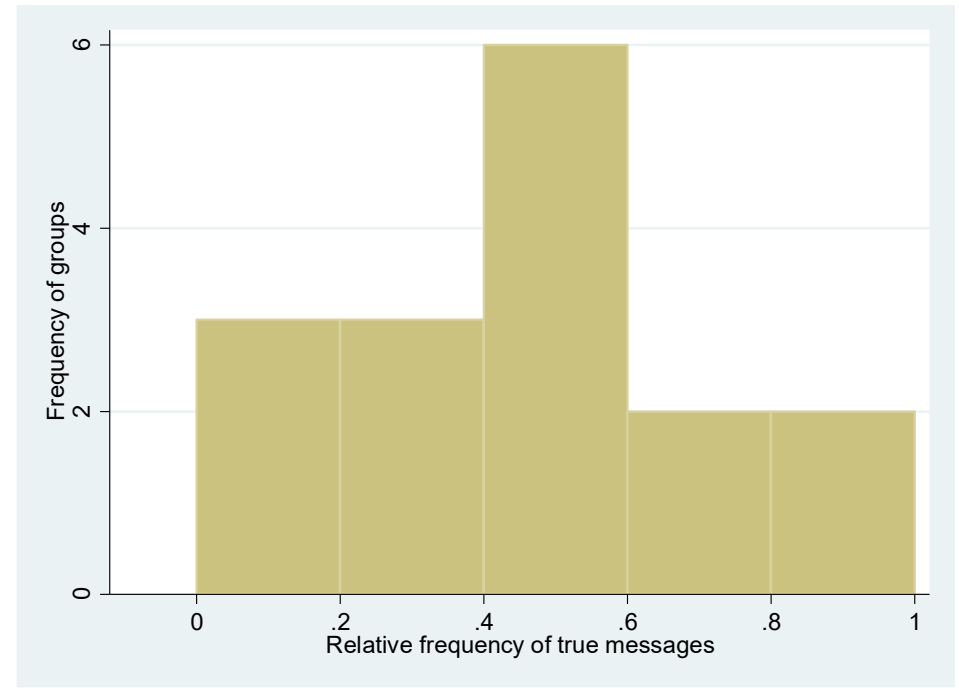


In Table F2, we report the content of the received reports in each block of 10 rounds in the Soft treatment. We observe that the frequency of truthful reports is roughly the same in the two halves of the experiment (approximately 50\%), so it should not have an important impact on payoffs.

Table F2. Distribution of type of received reports by blocks of rounds in the Soft treatment - absolute number of observations and relative frequencies ( $\%$ over row total)

\begin{tabular}{|c|c|c|c|c|}
\hline & 0 report & False report & Truthful report & Total \\
\hline Rounds 1-10 & $\begin{array}{c}16 \\
(32.65)\end{array}$ & $\begin{array}{c}9 \\
(18.37)\end{array}$ & $\begin{array}{c}24 \\
(48.98)\end{array}$ & $\begin{array}{c}49 \\
(100)\end{array}$ \\
\hline Rounds 11-20 & $\begin{array}{c}4 \\
(15.38)\end{array}$ & $\begin{array}{c}9 \\
(34.62)\end{array}$ & $\begin{array}{c}13 \\
(50.00)\end{array}$ & $\begin{array}{c}26 \\
(100)\end{array}$ \\
\hline Total & $\begin{array}{c}20 \\
(26.67)\end{array}$ & $\begin{array}{c}18 \\
(24.00)\end{array}$ & $\begin{array}{c}37 \\
(49.33)\end{array}$ & $\begin{array}{c}75 \\
(100)\end{array}$ \\
\hline
\end{tabular}

In Table F3, we separate groups into those with high-quality reports (those in which more than $50 \%$ of reports are truthful) and low-quality reports and show the average bids made by the buyers of reports in the auction, categorizing the cases in which (i) the content of the report is 0 , (ii) the content of the report does not coincide with the buyer's assigned value and (iii) the content of the report coincides with the buyer's assigned value. We report the number of observations within parentheses (as done in Table 2 in the main text for all groups).

Table F3. Average bids of buyers of reports, by average quality of reports in the group, content of the report and block of rounds

\begin{tabular}{|c|c|c|c|c|}
\hline & & $\begin{array}{c}\text { (i) } \\
\text { Content: } \\
0 \\
\text { [Prediction: 150] }\end{array}$ & $\begin{array}{c}\text { (ii) } \\
\text { Content: } \\
\text { Color }- \text { No } \\
\text { [Prediction: } 100]\end{array}$ & $\begin{array}{c}\text { (iii) } \\
\text { Content: } \\
\text { Color-Yes } \\
\text { [Prediction: } 200]\end{array}$ \\
\hline \multirow{3}{*}{$\begin{array}{l}\text { Low- } \\
\text { quality } \\
\text { reports }\end{array}$} & $\begin{array}{c}\text { Rounds } \\
1-10\end{array}$ & $\begin{array}{c}91.92 \\
(12)\end{array}$ & $\begin{array}{c}105.71 \\
(7)\end{array}$ & $\begin{array}{c}114.75 \\
(8)\end{array}$ \\
\hline & $\begin{array}{c}\text { Rounds } \\
11-20\end{array}$ & $\begin{array}{c}200.00 \\
(1)\end{array}$ & $\begin{array}{c}157.50 \\
(6)\end{array}$ & $\begin{array}{c}148.00 \\
(3)\end{array}$ \\
\hline & Total & $\begin{array}{c}100.23 \\
(13)\end{array}$ & $\begin{array}{c}129.62 \\
(13)\end{array}$ & $\begin{array}{c}123.82 \\
(11)\end{array}$ \\
\hline \multirow{3}{*}{$\begin{array}{l}\text { High- } \\
\text { quality } \\
\text { reports }\end{array}$} & $\begin{array}{c}\text { Rounds } \\
1-10\end{array}$ & $\begin{array}{c}100.00 \\
(4)\end{array}$ & $\begin{array}{c}149.50 \\
\text { (2) }\end{array}$ & $\begin{array}{c}124.87 \\
(16)\end{array}$ \\
\hline & $\begin{array}{c}\text { Rounds } \\
11-20\end{array}$ & $\begin{array}{c}156.67 \\
\text { (3) }\end{array}$ & $\begin{array}{c}132.00 \\
(3)\end{array}$ & $\begin{array}{c}182.80 \\
(10)\end{array}$ \\
\hline & Total & $\begin{array}{c}124.29 \\
(7)\end{array}$ & $\begin{array}{c}139.00 \\
(5)\end{array}$ & $\begin{array}{c}147.15 \\
(26)\end{array}$ \\
\hline
\end{tabular}


Focusing on the last 10 rounds, we observe that for those groups with high-quality reports, the average bids of buyers of reports are close to the equilibrium values, namely, 100 when not interested (case (ii)) and 200 if interested (case (iii)); for those with lowquality reports, the average bid is approximately 150 both when the report indicates that the buyer is not interested and when it indicates that she is interested. In any case, the number of observations is quite low.

In Figure F4, we show, for each group, the frequency of true messages (x-axis, quality of information) and the number of rounds in which at least one report was sold (y-axis) in the Soft treatment. The correlation coefficient $(0.25)$ is not significantly different from 0 (p-value 0.35 ). Thus, we do not find any relationship.

Figure F4. Relation between the size of the market for reports and the quality of reports

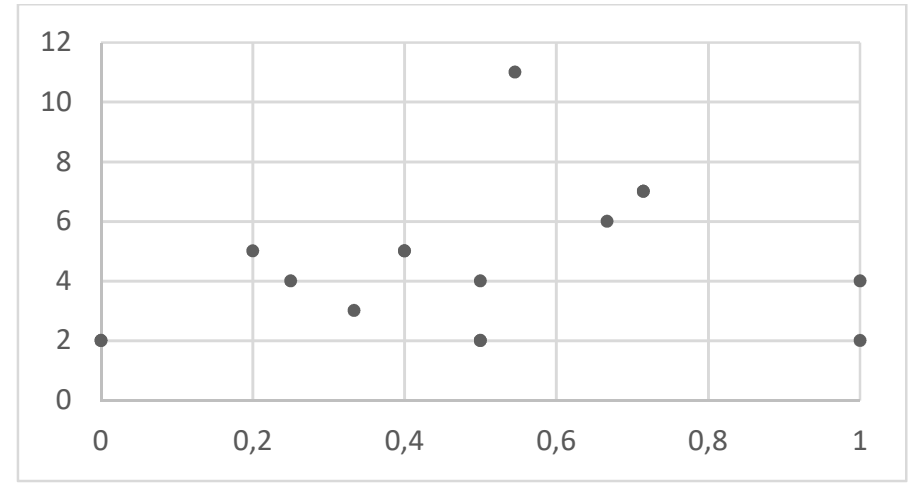

In Table F5, we explore the number of subjects who directly buy the information within groups and how frequently they subsequently post a price in each case in the Hard treatment. In the top panel, we report the absolute frequencies of groups by number of information acquirers (relative frequencies between parentheses). In the bottom panel, we report the frequencies of the decision to post a price in the market for reports, differentiating the cases in which the information acquirers are interested in the object and the cases in which they are not.

Table F5. Number of buyers of information within groups and frequencies of posted prices in each case in the Hard treatment

\begin{tabular}{|lcccc|}
\hline \# acquirers in the group & 0 & 1 & 2 & 3 \\
Frequency & 23 & 156 & 128 & 13 \\
& $(7.19)$ & $(48.75)$ & $(40.00)$ & $(4.06)$ \\
\hline \multirow{2}{*}{ Interested } & & $48 / 77$ & $81 / 126$ & \\
& & $(62.34)$ & $(64.29)$ & \\
\hline \multirow{2}{*}{ Uninterested } & & $56 / 79$ & $112 / 130$ & \\
& & $(70.89)$ & $(86.15)$ & \\
\hline
\end{tabular}


Regarding the number of acquirers within the group, we find that the modal play corresponds to just one informed player, as the equilibrium (reported in Proposition 2) predicts. However, we also find significant deviations, mainly to two players directly acquiring the information. Regarding the decisions to post a price, we note that in all four possible scenarios (interested/uninterested agents in the case of one/two directly informed agents), the modal choice is to post a price. In this respect, we should note that in the case of two potential sellers of information, it pays off to attempt to sell a report even when the seller is interested. Moreover, even in the case of only one potential seller of reports, if she believes that the other two players will buy a report from her, it requires a price of only 12.5 for the information-selling strategy to be better than (the equilibrium one of) not selling.

In Table F6, we present the frequency of buyers of reports by number of acquirers of information in the group (when at least one of them posts a price) in the Hard treatment. In the (equilibrium) case of there being one acquirer of information, $43 \%$ of the remaining players acquire a report (close to the equilibrium frequency of 50\%). However, in the (out-of-equilibrium) case of there being two acquirers of information, we find a large frequency of the remaining agents buying a report (in sharp contrast to the optimal behavior in this case of not buying a report). This might be due to some behavioral effect, such as an aversion to being the only uninformed person within a group.

Table F6. Buyers of a report by number of acquirers of information in the group in the Hard treatment

\begin{tabular}{|l|c|c|}
\hline \# potential sellers of reports in the group & 1 & 2 \\
\hline \# players who do not buy a report & 119 & 271 \\
& $(57.21)$ & $(21.77)$ \\
\hline \# players who buy a report & 89 & 97 \\
& $(42.79)$ & $(78.23)$ \\
\hline Total & 208 & 124 \\
& $(100)$ & $(100)$ \\
\hline
\end{tabular}

In Table F7, we show the frequencies of players in (the sequence) positions 1, 2 and 3 adopting the different roles (remaining uninformed, acquiring the information directly or buying a report) for both the Soft and Hard treatments. We observe that the frequency of players in positions 1, 2 and 3 adopting the different roles are very similar. We should, however, point out that actual payoffs are not the same as the theoretical ones, 
and the informed player obtains the lowest payoff, which may explain why so few of the first movers choose to be informed.

Table F7. Behavior in the information market, by treatment and player position

\begin{tabular}{|c|ccc|cccc|}
\hline \multicolumn{4}{|c}{ Hard } & \multicolumn{3}{c|}{ Soft } \\
\hline & Mover 1 & Mover 2 & Mover 3 & Mover 1 & Mover 2 & Mover 3 \\
\hline \multirow{3}{*}{ Uninformed } & 127 & 94 & 102 & 148 & 121 & 115 \\
& $(39.32)$ & $(29.10)$ & $(31.58)$ & $(38.54)$ & $(31.51)$ & $(29.95)$ \\
Informed & 140 & 159 & 152 & 163 & 197 & 201 \\
& $(31.04)$ & $(35.25)$ & $(33.70)$ & $(29.06)$ & $(35.12)$ & $(35.83)$ \\
Acquire report & 53 & 67 & 66 & 29 & 22 & 24 \\
& $(28.49)$ & $(36.02)$ & $(35.48)$ & $(38.67)$ & $(29.33)$ & $(32.00)$ \\
\hline
\end{tabular}

